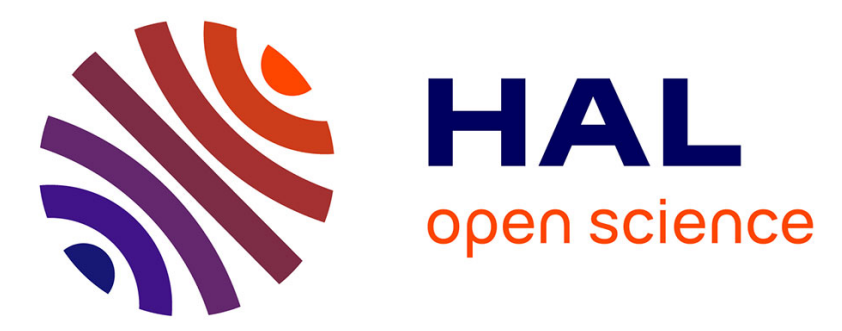

\title{
Le Bronze ancien de la vallée de la Seugne: La Palut à Saint-Léger (Charente-Maritime)
}

Jean-Marc Bouchet, Claude Burnez, Julia Roussot-Larroque, Alain Villes, Yves Gruet

\section{- To cite this version:}

Jean-Marc Bouchet, Claude Burnez, Julia Roussot-Larroque, Alain Villes, Yves Gruet. Le Bronze ancien de la vallée de la Seugne: La Palut à Saint-Léger (Charente-Maritime). Gallia Préhistoire - Fouilles et monuments archéologiques en France métropolitaine, 1990, 32, pp.237-275. 10.3406/galip.1990.2334 . hal-02409183

\section{HAL Id: hal-02409183 \\ https://hal.science/hal-02409183}

Submitted on 17 Dec 2019

HAL is a multi-disciplinary open access archive for the deposit and dissemination of scientific research documents, whether they are published or not. The documents may come from teaching and research institutions in France or abroad, or from public or private research centers.
L'archive ouverte pluridisciplinaire HAL, est destinée au dépôt et à la diffusion de documents scientifiques de niveau recherche, publiés ou non, émanant des établissements d'enseignement et de recherche français ou étrangers, des laboratoires publics ou privés.

\section{(1) (1) $\$$}

Distributed under a Creative Commons Attribution - NonCommercial - NoDerivatives| 4.0 


\title{
LE BRONZE ANCIEN DE LA VALLÉE DE LA SEUGNE : LA PALUT À SAINT-LÉGER (CHARENTE-MARITIME)
}

\author{
par Jean-Marc BOUCHET, Claude BURNEZ, Julia ROUSSOT-LARROQUE et Alain VILLES
}

\begin{abstract}
RÉsumé
Dans la basse vallée de la Seugne, à La Palut (Saint-Léger, Charente-Maritime), un important ensemble de mobilier archéologique (3000 tessons, plus de 700 témoins lithiques façonnés, quelques outils en os et parures) a dé découvert lors de travaux dans un marais, puis dans un sondage fait pour repérer les niveaux archéologiques place. Outre d'intéressants vestiges résiduels (Artenac et Campaniforme), ce mobilier comporte une série de vases reconstituables, dont les formes et décors révèlent un style céramique particulier, suggérant l'existence di) n complexe culturel original du Bronze ancien, se prolongeant éventuellement dans le Bronze moyen gional. Des éléments de ce complexe sont identifiés dans le mobilier d'autres sites de la région. La datation, les Wii gines possibles et les affinités de ce complexe culturel, en particulier ses relations avec le Campaniforme, sont ex эminées; un inventaire des éléments comparables est proposé et fait l'objet d'une carte de répartition.
\end{abstract}

\section{ABBSTRACT}

At La Palut (Saint-Léger, Charente-Maritime), situated in the lower valley of the Seugne, significant archaeological finds (3000 sherds, more than 700 flints, a few bone objects and ornaments) have been recovered from the debris after a drainage in the marshlands. The site was later confirmed by a trial test excavation undertaken in order to localise the probable in situ archaeological levels. Apart from interesting evidence of the Artenac and Bell Beaker cultures, the finds include various pots the shapes and decorations of which suggest a style of pottery belonging to an original Early Bronze Age group probably coinciding partly with the regional Middle Bronze Age. Similar components of this group have been found on other sites of the district. The dating, origin and relationship of this cultural group, and more precisely its relationship with the Beakers, are discussed, and illustrated by a distribution map.

En juin 1985, un curage de fossé à la pelle mécanique fut entrepris au hameau de La Lijardière à Saint-Léger pour retrouver des fondations de pierres qui, selon la tradition, entouraient la fontaine de La Palut. Au cœur de la source, le creusement fut vainement poussé au maximum de la capacité de l'engin; il est difficile d'évaluer la profondeur qui fut réellement atteinte. Un recalibrage restreint des chenaux d'écoulement fut effectué dans le cadre de cette opération. Cette source communique, en amont et en aval, avec un petit bras de la rive gauche de la
Seugne, qui se sépare de la rivière le long de la basse terrasse rissienne de La Chapelle de l'Ile, pour la rejoindre ensuite au Moulin du Gua. Il s'agit d'un cours naturel, probablement aménagé, qui draine le bas de pente des coteaux du Campanien au pied du hameau pour faciliter l'écoulement des eaux pendant les inondations et les fortes pluies.

En octobre de la même année, J.-M. Bouchet découvrit les premiers vestiges archéologiques sur les déblais et vint les montrer à $\mathrm{C}$. Burnez et $\mathrm{A}$. Villes qui avaient alors entrepris un sondage à proximité, 


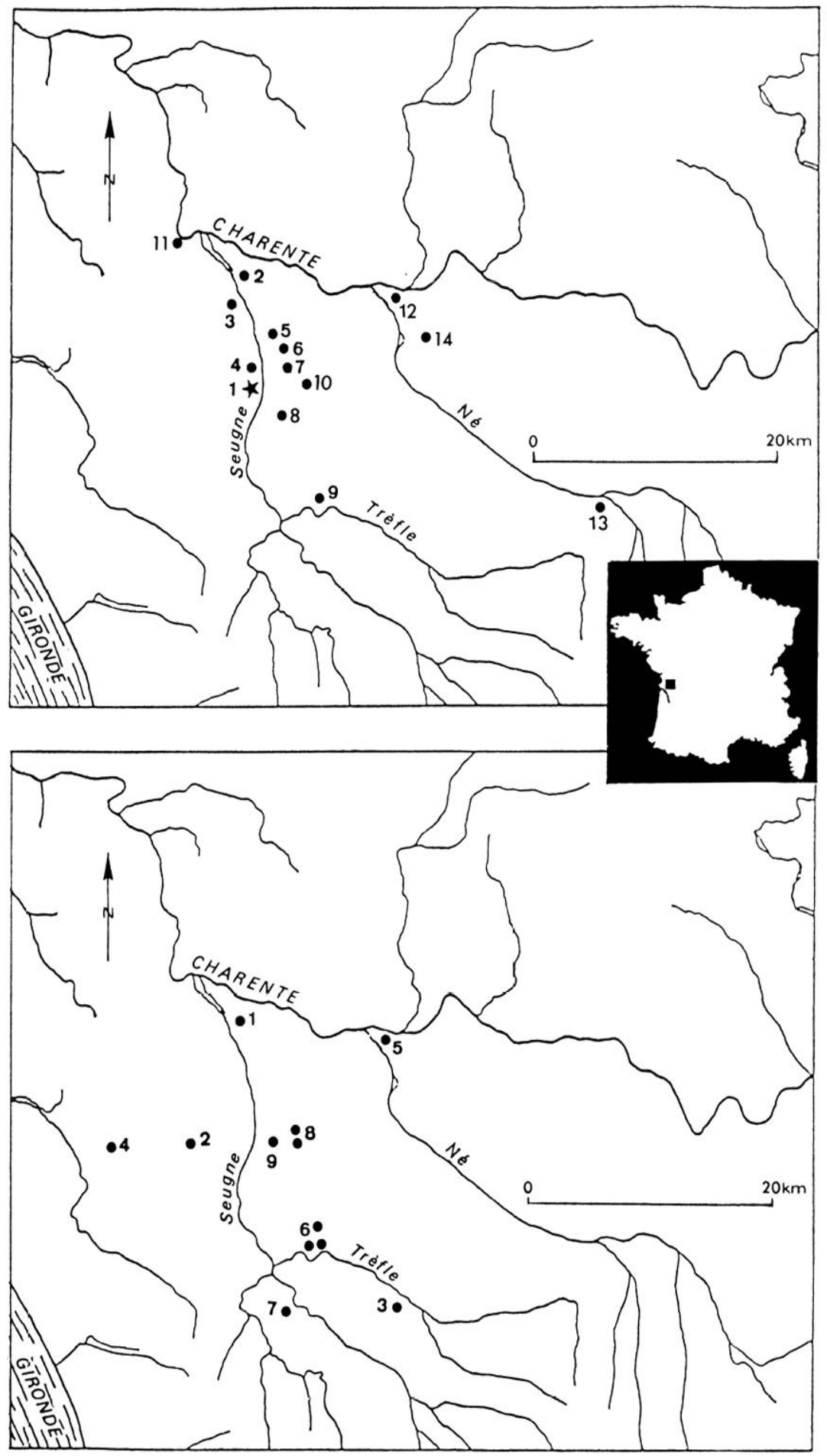

Fig. 1 - En haut, sites à céramique du Bronze ancien du bassin de la Seugne.

Charente-Maritime : 1, La Palut à Saint-Lèger; 2, Les Orgeries à Courcoury; 3, Chez Coindreau à Colombiers; 4, L'Entrée à Colombiers; 5 , Jarlac à Montils; 6 , La Cornelle à Montils; 7, Les Guédards à Montils; 8 , Chez les Brungs à Biron; 9 , Cordis à Marignac; 10, Les Grands Près à Saint-Seurin-de-Palenne; 11, Diconche à Saintes.

Charente: 12, Le Vieux Bourg à Merpins; 13, La Font-Rase à Barbezieux-Saint-Hilaire; 14, Font-Belle à Segonzac.

En bas, sites à objets métalliques du Bronze ancien et moven du bassin de la Seugne.

Charente-Marilime : 1, Gàtebourse à Courcoury ; 2, La Carcaudrie à Villars-en-Pons ; 3 , Réaux ; 4, Gémozac ; 6, Cordis à Marignac : 7 ,

Le Fief à Clion; 8, Biron; 9, "La Charnet" (?) à Pons.

Charente: 5, Le Vieux Bourg à Merpins. 
dans la vallée de la Seugne. Vu l'importance de la découverte et les menaces de destruction par le passage incessant des troupeaux, la Direction des Antiquités, informée, confia immédiatement la responsabilité du sauvetage à C. Burnez.

\section{LE SITE}

Dans son cours inférieur, en aval de Pons, la Seugne, petit affluent de la rive gauche de la Charente, coule en formant de nombreux méandres dans une large vallée marécageuse et tourbeuse dont la richesse en sites néolithiques et protohistoriques était restée insoupçonnée avant les prospections de J.-M. Bouchet (fig. 1, en haut). Sur les hauteurs environnantes, on connaissait pourtant déjà quelques-uns des grands sites classiques du Néolithique récent de la région (Peu-Richard, Le Chaillot de la Jard, Le Mourez de Berneuil). Dans le même secteur, les prospections aériennes de J. Dassié révèlent une extraordinaire densité de structures archéologiques, d'époques variées, entre autres les camps à fossés néolithiques de Diconche à Saintes, La Combe à Bouyer et Le Marais des Vaches à Montils, Pont d'Husson à Bougneau et de nombreux enclos circulaires. Dans ce contexte, les marais de la Seugne ont certainement joué un rôle important: les premières traces d'implantation humaine remontent au Cardial mais c'est surtout au Néolithique final et au Bronze ancien (fig. 1, en haut) qu'elles deviennent abondantes, du moins en l'état actuel des prospections.

\section{LES FOUILLES}

Pour commencer, une masse considérable de déblais qui, de toute évidence, ne contenait pas partout des vestiges préhistoriques, a été fouillée sur une centaine de mètres carrés. Les dépôts, d'épaisseur variant de quelques centimètres à plus de $60 \mathrm{~cm}$, ont été tamisés, d'abord à sec puis à l'eau, par J.-M. Bouchet et C. Burnez qui y ont consacré 200 heures. Avec l'aide des deux autres signataires de l'article et de S. Burnez, A. Bouchet et M.-C. Lagarde, le sauvetage put être terminé fin novembre, avant que les inondations ne recouvrent le gisement.

En 1986, un sondage à la pelle mécanique fut effectué avec l'accord de la Direction des Antiquités pour tenter de localiser la (ou les) couche(s) archéologique(s) en place. A proximité du cœur de la source fut traversée une couche homogène d'argile noire, d'environ 1,50 m d'épaisseur, stérile, qui à cet endroit reposait directement sur la roche en place. La montée très rapide des eaux montra que, pour une fouille future, il faudrait prévoir un rabattement de la nappe phréatique. En juillet 1987, Jean-Lionel Henriet, prospecteur subaquatique de la Société d'Archéologie et d'Histoire de la Charente-Maritime, examina en plongée l'excavation laissée par la pelle mécanique et remonta quelques tessons recueillis en place. Selon son rapport "cette excavation se situe à $80 \mathrm{~cm}$ en dessous du niveau actuel de la nappe phréatique. Trois niveaux ont pu être localisés : le premier, tourbeux-argileux, est compact, le deuxième est composé de sable et de cailloux tandis que le troisième est essentiellement sableux. Le matériel recueilli se situe pour l'ensemble dans le deuxième niveau. Son épaisseur est d'environ $40 \mathrm{~cm}$. Enfin, la présence de pierres plates semble indiquer l'existence d'un ancien passage, mais l'assèchement de ce point d'eau permettrait d'infirmer ou d'affirmer ce dernier point".

Le gisement demeurant très menacé par l'érosion du courant, d'une part, et d'autre part par des projets "d'assainissement" du marais, il était nécessaire de tenter de déterminer l'importance de la couche qui pourrait être éventuellement fouillée. En 1988, un nouveau sondage fut effectué avec les moyens de pompage nécessaires, vu les difficultés rencontrées antérieurement. Pour cette intervention localisée plus en amont de la source, B. Passini et M. Gruet apportèrent leur précieuse collaboration.

En premier lieu, l'entreprise ouvrit un sondage sur la rive gauche (fig. 2a) qui rencontra la rochemère immédiatement sous les tourbes argileuses. De toute évidence, la couche archéologique, sable et terre, ne pouvait donc se trouver que vers l'aval, sous l'île. En conséquence, des barrages en terre furent établis, l'un en amont, l'autre en aval, pour tenter de détourner la source du ruisseau. Le niveau d'eau stabilisé, il devint évident qu'il ne s'agissait pas en fait d'une source, mais de multiples infiltrations provenant à la fois de la nappe phréatique et du ruisseau. Les pompes mises en action ne réussirent pas à assécher la zone comprise entre les barrages.

Dans ces conditions, nous avons dû nous contenter de repérer manuellement le niveau archéologique dans les coupes faites à la pelle mécanique. La stratigraphie a ainsi pu être établie, avec une précision relative, en trois points : A, B et $\mathrm{C}$ (fig. $2 \mathrm{~b}$ ). 


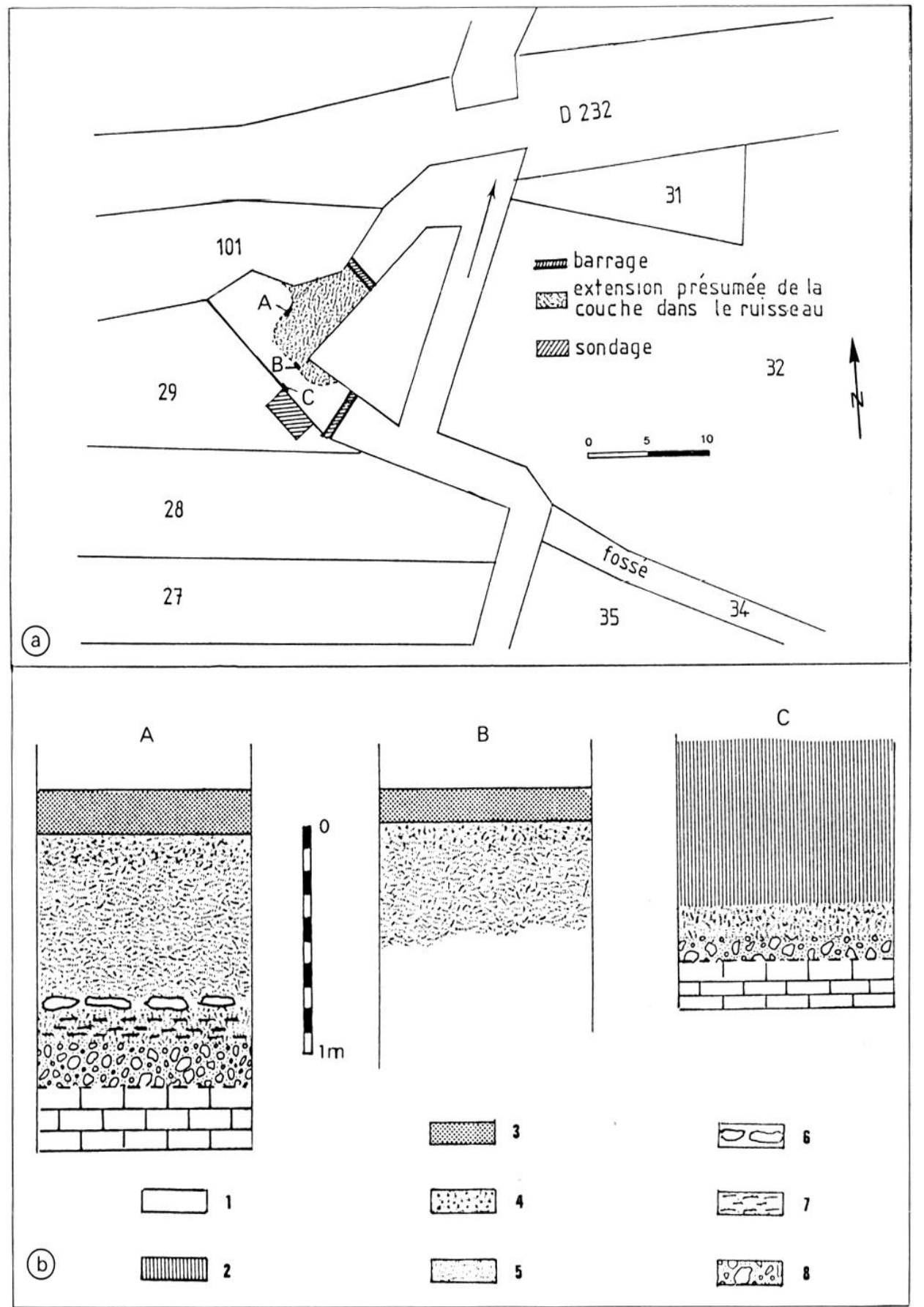

Fig. 2 - La Palut, sondage 1988. a, plan de situation du sondage et des relevés stratigraphiques; $b$, stratigraphie aux points A, B et $\mathrm{C}: 1$, eau $; 2$, argile tourbeuse $; 3$, vase molle $; 4$, sable coquillier $; 5$, sable $; 6$, lit de pierres $; 7$, couche archéologique $; 8$, calcaire en décomposition.

\section{LA STRATIGRAPHIE}

En A (fig. 2b), sous la couche d'eau très boueuse de 20 à $25 \mathrm{~cm}$, un niveau de sable coquillier, d'une quinzaine de centimètres, surmonte un sable fin, lui-même reposant sur des pierres calcaires, probablement un blocage que J.-L. Hen- riet avait interprété comme un "passage» lors de sa plongèe. Cet ensemble de dépôts sableux peut atteindre $70 \mathrm{~cm}$ d'épaisseur totale. Sous les pierres, un sable grisâtre, en partie terreux, renferme les vestiges archéologiques. Il ne semble pas excéder, en cet endroit, une quinzaine de centimètres et repose sur du calcaire altéré provenant de la décomposition de la roche-mère. 
En B, sous la même couche de vase molle, nous avons rencontré le sable coquillier contenant des objets médiévaux et modernes, puis le sable fin. Nous n'avons pas pu en évaluer l'ampleur, mais à cet endroit le godet a raboté la roche-mère au moins $70 \mathrm{~cm}$ plus bas.

En C, c'est-à-dire à l'aplomb des berges, sous la tourbe argileuse qui les compose, nous avons retrouvé le sable coquillier, plus en profondeur qu'en $\mathrm{A}$ et $B$, et reposant selon toute vraisemblance sur la roche-mère qui avait été mise au jour dans le sondage préliminaire.

De toute évidence, la couche archéologique existe sous une épaisseur assez importante aux alentours de l'île et probablement sous celle-ci. Cette situation semble comparable à celle du site campaniforme de La Grande Pigouille à Belluire, inclus dans une formation éolienne dans la basse vallée d'un affluent de la Seugne. Dans les deux cas, il s'agirait d'occupations installées sur la terre ferme et ennoyées par la suite (Bouchet, Burnez, Fouéré, à paraitre). Les difficultés d'exploration expliquent seulement en partie les divergences des lectures stratigraphiques : les différences relevées entre les points $A, B$ et $C$ ne tiennent pas seulement aux difficultés de lecture, mais peut-être aussi aux conditions de dépôt particulières à ce milieu.

Les vestiges archéologiques, peu nombreux mais typiques (fig. 18), recueillis lors de cette intervention seront décrits avec le mobilier du premier sauvetage.

\section{LE MOBILIER}

A ce jour, plus de 3000 tessons et plus de 700 témoins lithiques façonnés ont été recueillis ainsi qu'une industrie de l'os et du bois de cerf, des bois travaillés, des objets de parure, quelques coquilles de bivalves marins, de la faune et quelques fragments d'os humains. Les conditions de gisement ne permettent pas d'attribuer faune, bois travaillé et os humains à une phase précise de l'occupation du site. Dans la faune, assez peu abondante et mal conservée, on notera l'abondance du Cheval. Quant aux ossements humains, fragment d'occipital d'adulte, très robuste, et phalange, on ne saurait affirmer qu'ils sont en relation avec les objets de parure.

Le classement du mobilier s'appuiera donc avant tout sur des critères typologiques, et secondairement sur l'état du matériel et la situation topographique des trouvailles. Ainsi, l'état fragmenté et roulé des vestiges artenaciens suggère qu'ils devaient être à la base du dépôt, et ont dû particulièrement subir les effets de la montée des eaux. D'autre part, les déblais ayant été carroyés avant tamisage, nous avons constaté que les témoins de l'Âge du Fer se trouvaient à la périphérie de la zone livrant le mobilier du Bronze ancien.

\section{L'indUSTRIE LithiQUe}

\section{LE SILEX}

Les matières premières utilisées sont assez variées mais on trouve surtout le silex gris foncé du Campanien. Les autres sources locales d'approvisionnement n'ont pas été négligées : le silex rubané grisblond des ateliers du Douhet-Taillebourg et d'Écoyeux, les silex des terrasses (en majorité blonds) et le silex calcédonieux local. Le silex importé du Grand-Pressigny a été utilisé pour quelques pièces, dont deux fragments de poignards (fig. $3, \mathrm{n}^{\circ} 6$ et fig. $4, \mathrm{n}^{\circ} 35$ ) et une "scie" à coche (fig. $4, \mathrm{n}^{\circ} 34$ ). Sauf spécification contraire, l'outillage est en silex gris foncé du Campanien, à cortex blanchâtre relativement frais.

Nous avons décompté 87 outils :

6 flèches perģantes dont une ébauche de flèche foliacée à retouches couvrantes et pointe brisée; une ébauche de flèche à pédoncule et ailerons peu développés (fig. $3, \mathrm{n}^{\circ} 2$ ); une à pédoncule et ailerons peu développés, cassés (fig. $3, n^{\circ} 4$ ); une autre à pédoncule et ailerons subcarrés (fig. $3, n^{0} 1$ ); une autre à pédoncule et ailerons carrés à retouche couvrante, très belle (fig. $3, \mathrm{n}^{\circ} 5$ ); une, enfin, de forme lancéolée, à ailerons plus longs que le pédoncule et recourbés vers l'intérieur (fig. $3, n^{\circ} 3$ );

2 fragments de poignards : le premier est la partie distale d'un poignard unifacial, en silex du GrandPressigny, avec traces de polissage dorsal et retouche semi-abrupte irrégulière des bords (fig. $3, n^{\circ} 6$ ); le second est un tronçon mésial, unifacial, en silex du Grand-Pressigny également, à dos presque entièrement poli et retouche très courte des bords (fig. 4 , $\left.\mathrm{n}^{\circ} 35\right)$;

5 microlithes dont un trapèze du Martinet à retouche inverse plate de la base (fig. $3, n^{\circ} 18$ ); trois formes atypiques, la première à troncature concave opposée à une troncature sinueuse, la deuxième à troncature normale opposée à une troncature oblique, alternativement directe et inverse, la troisième enfin à encoche distale directe et inverse, et retouche inverse plate du bord contigu;

31 grattoirs dont 4 simples sur éclat court; 6 sur éclat long dont 2 sur éclat cortical; 2 sur éclat 

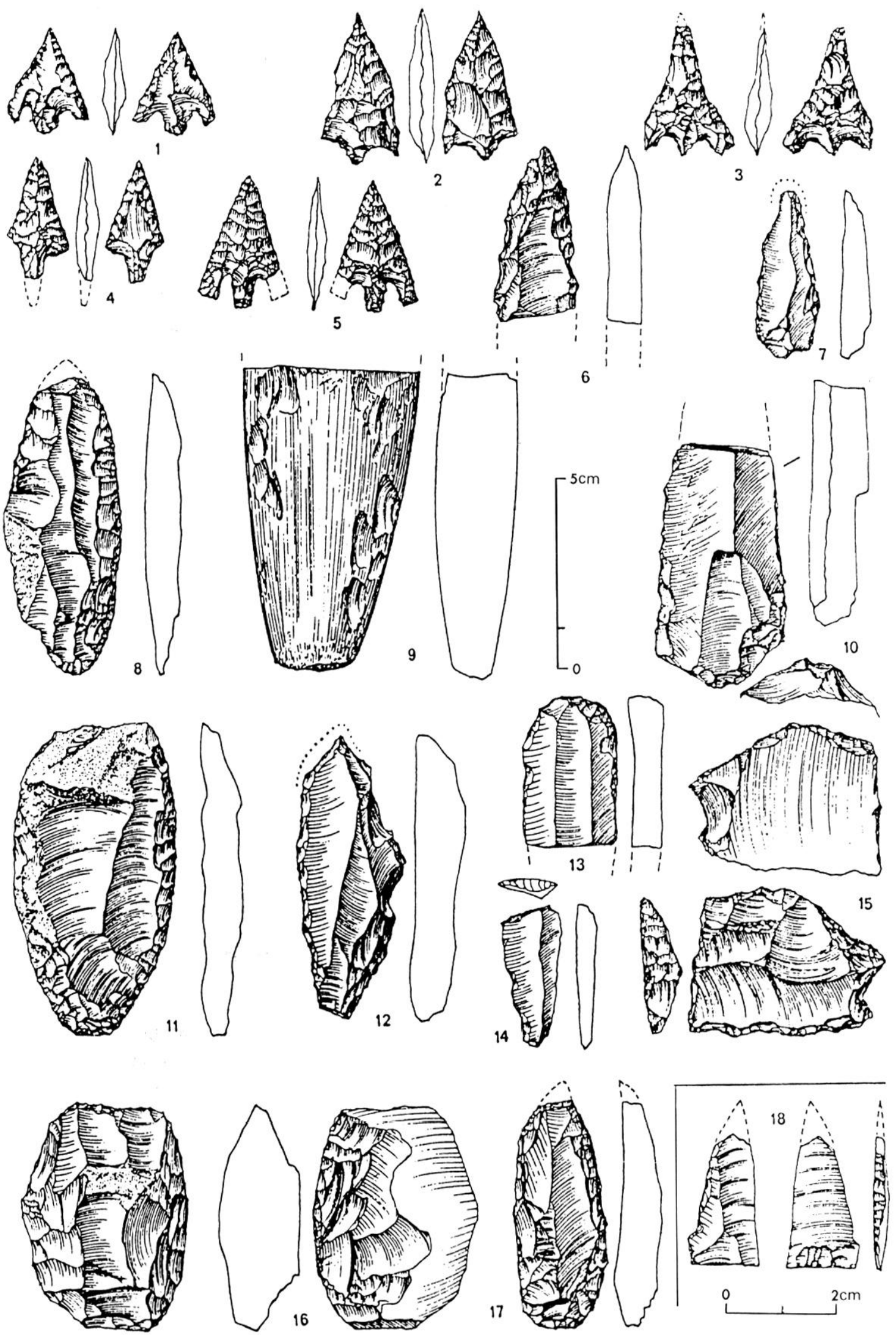

Fig. 3 - La Palut, industrie lithique : 1-5, flèches perçantes; 6 , partie distale de poignard ; 7 perçoir ; 8, 11, 16, 17, racloirs latéraux ou "couteaux"; 9 , fragment de hache polie $; 10,14$, lames ébréchées; 12 , pointe sur fragment probable de poignard ; 13 , grattoir ; 15 , fragment de "scie" à coche; 18 , trapèze du Martinet. 
retouché court; 6 sur éclat retouché long, dont 1 composite, avec un bord retouché en racloir; 1 en bout de lame, opposé à une troncature (fig. $3, \mathrm{n}^{\circ} 13$ ); 1 denticulé à retouche alternante sur un bord; 1 double; 2 circulaires sur éclat cortical et 1 micrograttoir ;

15 racloirs ou "couteaux" dont 13 en silex gris foncé du Campanien; 2 autres sont, l'un en silex calcédonieux, l'autre en silex blond. Deux d'entre eux sont à coches ("scies" à coches) : le premier (fig. 4, $\mathrm{n}^{\circ} 34$ ), en silex du Grand-Pressigny, est fait sur éclat quadrangulaire mince à coins arrondis et porte une retouche directe plate; le second (fig. 3, $\left.\mathrm{n}^{\circ} 15\right)$ a été réutilisé avec troncature partielle sur cassure; un racloir ovalaire à retouche abrupte sur un bord et semi-abrupte sur l'autre; un racloir sur éclat épais, ovalaire, avec un bord à retouche directe abrupte et retouche inverse plate du même bord (fig. $3, \mathrm{n}^{\circ} 16$ ); un racloir ovalaire sur éclat long à retouche semi-abrupte sur un des bords et retouche marginale irrégulière et coche inverse à l'extrémité distale (fig. $\dot{3}, \mathrm{n}^{\circ} 8$ ); un racloir double latéral associé à un front de grattoir distal à retouche presque plate; un racloir double sur éclat allongé à retouche marginale; un racloir sur éclat ovale allongé à retouche semi-abrupte d'un bord; un racloir simple transversal sur éclat épais, à retouche denticulée, abrupte sur un bord et à la partie proximale; un racloir double ogival sur éclat cortical épais à retouche plate; un racloir double sur éclat ovale plat à retouche irrégulière; un racloir double ovale sur éclat, avec un petit bec dégagé par deux encoches distales, en silex calcédonieux; un racloir simple à encoche inverse, retouche d'amincissement éliminant le bulbe, partie utile convexe à retouche plate; un racloir double sur éclat allongé à retouche partielle et irrégulière d'un bord; un racloir en silex blond brisé à l'extrémité distale : on note une plage polie à l'extrémité distale sur la face dorsale et un lustré, également distal, sur la face ventrale ainsi qu'un coup de burin (intentionnel?) sur fracture, avec une retouche inverse du bord opposé au coup de burin;

1 petite raclette a une retouche abrupte sur deux bords, dont l'un porte, en outre, quelques retouches inverses plates;

des perçoirs et becs dont une pièce en silex grisblond à deux becs opposés, sans doute sur fragment de poignard, les deux bords sont à retouche semiabrupte, l'un d'eux est denticulé (fig. $3, \mathrm{n}^{\circ} 12$ ); un bec sur éclat, dont un bord est denticulé, l'autre abrupt, à retouche semi-abrupte et coche; un bec sur éclat à retouche denticulée des deux bords. Deux perçoirs: l'un sur éclat de silex calcédonieux à pointe dégagée par retouche directe d'un côté, inverse de l'autre, le second en bout de lame à retouche bilatérale abrupte et irrégulière, pointe très usée (fig. $3, \mathrm{n}^{\circ} 7$ );

divers : un corps de lame à retouche courte du bord droit, retouche irrégulière du bord gauche, en silex roux opaque (fig. $3, \mathrm{n}^{\circ} 10$ ); un fragment de petite lame à retouche abrupte partielle sur un bord, inverse plate sur l'autre, et coche basale; un éclat ovale mince à retouche directe plate sur un bord, inverse partielle et irrégulière sur l'autre; un éclat de ravivage de nucléus épais à retouche denticulée sur la partie distale; un éclat laminaire cortical à retouche marginale directe et inverse, irrégulière sur un bord, retouche abrupte inverse partielle sur l'autre, et troncature partielle; un éclat plat à retouche semi-abrupte directe continue sur un bord, et légèrement denticulée sur l'autre bord; un éclat allongé à retouche denticulée continue sur les deux bords et sur la partie transversale; un éclat épais à retouche abrupte sur un bord, fortement lustré sur la partie proximale; un éclat cortical allongé à retouche continue sur un bord et troncature distale; une petite lame à troncature distale et retouche d'utilisation discontinue sur les deux bords (fig. $3, \mathrm{n}^{\circ} 14$ ); un éclat allongé, denticulé sur les deux bords, front oblique à retouche abrupte; un éclat à troncature très oblique et bords denticulés; l'un des bords porte en outre une retouche inverse;

\section{1 petit pic de section triédrique;}

1 ébauche de hache taillée en silex gris clair de Taillebourg dont les arêtes sont fortement écrasées et émoussées ;

1 fragment de hache polie (côté talon) en silex blond, à section ovalaire; il porte de légers méplats latéraux, un polissage incomplet des flancs et des enlèvements partant de la cassure (fig. $3, n^{0} 9$ ).

\section{LES AUTRES ROCHES}

Un galet allongé avec traces d'utilisation en biseau aux deux extrémités (estèque?); un fragment de grès à grain fin provenant probablement d'une meule ou d'un polissoir, avec traces de reprise d'utilisation sous forme de polissage partiel d'une cassure; un fragment de roche microgrenue (galet), avec traces de débitage sur les bords et traces d'écrasement sur une arête; enfin un fragment d'aiguisoir en roche microgrenue, de section rectangulaire, entièrement poli sur les quatre faces. 


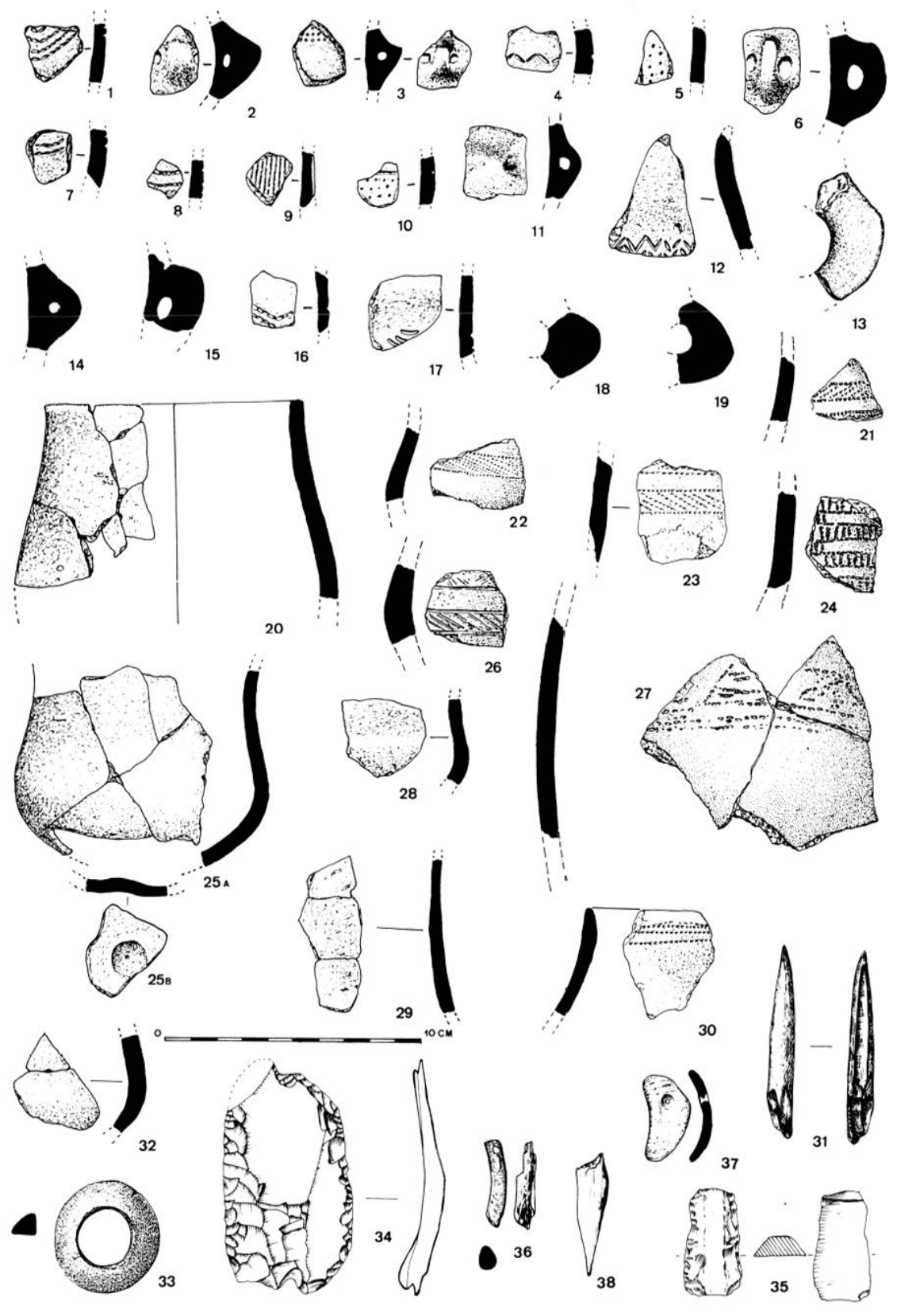

Fig. 4-La Palut : 1-19, céramique d'Artenac ; 20-30, 32, céramique campaniforme ; 31,38 , poinçons en os ; 33, anneau tronconique en os; 34 , "scie" à coche en silex du Grand-Pressigny; 35 , poignard en silex du Grand-Pressigny; 36 , pendeloque en lignite; 37 , pendeloque en griffe en test de Cardium.

L'INDUSTRIE DE L'OS ET DU BOIS DE CERF

Peu abondante, elle comporte quatre poinçons : l'un obtenu par sciage d'une diaphyse dont la partie proximale manque (fig. $4, \mathrm{n}^{\circ} 31$ ), les trois autres sont sur esquilles dont seule l'extrémité utile est polie. Le bois de cerf est représenté par quatre fragments de cornillons dont l'un présente des traces de sciage.

\section{LES OBJETS DE PARURE}

Ils comprennent une pendeloque en griffe, en test de bivalve (Cardium?) à perforation biconique (fig. $4, \mathrm{n}^{\circ} 37$ ), une pendeloque arciforme incomplète en lignite (fig. $4, \mathrm{n}^{\circ} 36$ ) et un anneau tronconique en os parfaitement poli et travaillé (fig. $4, \mathrm{n}^{\circ} 33$ ). On doit peut-être y ajouter un fragment de coquille de Cardium non travaillé. 


\section{La CÉramique}

\section{La céramique artenacienne}

Peu abondante, très fragmentée et mal conservée, elle comprend presque toute la gamme des décors classiques de l'Artenacien: pointillé, pointillé-traîné, chevrons, chevrons emboîtés, zigzags et quelques anses nasiformes (fig. 4, $\mathrm{n}^{\text {os }} 1-19$ ). Aucune forme n'est reconstituable.

\section{La céramique campaniforme}

Beaucoup mieux conservée, avec des remontages ayant permis des reconstitutions partielles de formes, elle est néanmoins en partie érodée. La plupart des tessons sont fins, souvent rouges, parfois gris ou bruns. Les décors sont faits au peigne, sauf le $n^{\circ} 26$ de la figure 4 qui est incisé. On note des bandes hachurées (fig. $4, \mathrm{n}^{\text {os }}$ 21-23), de sens contrarié dans un cas ( $\mathrm{n}^{\circ} 23$ ), des bandes au remplissage de traits verticaux ( $\left.n^{\circ} 24\right)$, des triangles pointe en haut ( $n^{\circ} 27$ ) et une bande de trois lignes pointillées horizontales près du bord ( $\left.n^{\circ} 30\right)$. Il est possible que certains aient été incrustés de blanc. La pâte et la forme permettent d'attribuer au Campaniforme de nombreux fragments sans décor $\left(\mathrm{n}^{\text {os }} 28,29,32\right)$ dont la partie supérieure d'un gobelet peu galbé $\left(n^{\circ} 20\right)$ et la base d'un petit gobelet à profil plus sinueux auquel on pourrait associer un petit fond ombiliqué de même aspect ( $\left.\mathrm{n}^{\text {os }} 25 \mathrm{~A}, \mathrm{~B}\right)$. Au total on peut estimer à dix minimum les vases campaniformes individualisés.

\section{La céramique du Bronze ancien}

Nettement plus abondante et mieux conservée que la céramique artenacienne et les Campaniformes, la céramique du Bronze ancien de La Palut forme l'essentiel des vestiges retirés de la fontaine. Elle fournit un répertoire de formes et de décors que leur variété même rend difficile à sérier. On distingue :

Les vases à décor à la cordelette et pseudo-cordé (fig. $5, n^{\text {os }} 1-20,22,25$ et fig. $18, n^{\text {os }} 4,7,8$ ) en lignes parallèles horizontales (fig. $5, \mathrm{n}^{\mathrm{os}} 2,5,7,8,11,12,14$ $16,18,20$ et fig. 18, $\mathrm{n}^{\circ} 8$ ), verticales (fig. $5, \mathrm{n}^{\mathrm{os}} 6,13$ ), en chevrons (fig. $5, \mathrm{n}^{\text {os }} 4,9,10,19$ et fig. $18, \mathrm{n}^{\text {os }} 4,7$ ), dans un cas à côté d'un cordon en fer à cheval (fig. $18, n^{\circ} 7$ ), en vagues (fig. $5, n^{\text {os }} 1,3$ ) et, dans deux cas au moins, en panneaux orthogonaux encadrant un mamelon enfoncé (fig. $5, \mathrm{n}^{\text {os }} 17,22$ ). La forme biconique semble prédominer. L'un de ces vases porte au col un décor cordé et sur la panse des coups d'ongle très serrés (fig. $5, n^{\circ} 17$ ), d'autres vases, de même forme, ne portent que des coups d'ongle (fig. $5, n^{\circ} 21$ ) ou des décors pseudo-cordés exécutés par diverses techniques et parfois disposés également en panneaux orthogonaux (fig. 5, $\mathrm{n}^{\text {os }} 23,24$ ). Ces vases ont en commun des pâtes fines à dégraissant peu visible, de couleur claire, jaune orangé pour la plupart.

Un unique vase ovale (fig. $5, \mathrm{n}^{\text {os }} 26 \mathrm{~A}, \mathrm{~B}, \mathrm{C}$ ), particulier à la fois par sa pâte grise onctueuse, son décor et sa forme, est difficile à interpréter car incomplet. Il porte des bandes verticales à remplissage de sillons fins et serrés, bordées de triangles hachurés et frangées à leur extrémité; le fond (?), entouré d'une bande hachurée et dentelée, est orné de cannelures parallèles.

Les récipients petits et moyens à anse probablement unique sur le bord (fig. $6, \mathrm{n}^{\text {os }} 1,2,4-6,9,13$ ). Les parties conservées ne permettent pas de décider si leurs fonds étaient ronds ou plats; les anses sont. rubanées et, dans un cas, cannelée verticalement $\left(n^{\circ} 4\right)$. Dans cette catégorie, l'exemplaire le mieux conservé, fin, gris-beige, très bien cuit, est de forme biconique; un décor pointillé en losanges occupe la partie supérieure; il chevauche la carène et encadre l'anse ( $n^{\text {os }}$ 1A, B); une tasse ( $n^{\circ} 9$ ) est couverte d'impressions d'ongle profondes et serrées, sauf près du bord; la pâte noire est d'une cuisson plutôt médiocre; les autres fragments $\left(\mathrm{n}^{\text {os }} 2-6,13\right)$ ne portent pas de décor dans la partie conservée.

Les vases globuleux légèrement refermés à décor pointillé (fig. $6, \mathrm{n}^{\mathrm{os}} 7,8,10,11$ ). Le décor du $\mathrm{n}^{\mathrm{0}} 10$ forme des damiers et ce vase porte des boutons (au moins deux) près du bord ; un autre possède au moins un bouton au diamètre maximum ( $\left.n^{\circ} 11\right)$. Deux petits fragments $\left(\mathrm{n}^{\text {os }} 7,8\right)$ présentent un décor assez proche du premier; sur le $n^{\circ} 8$, incomplet, ne subsiste qu'une bande horizontale. Un mamelon à perforation verticale proche du bord ( $\left.n^{\circ} 12\right)$ semble, d'après son aspect, appartenir à l'ensemble décrit précédemment.

Les vases à décor plastique, de formes varièes, sont malheureusement très fragmentaires, avec souvent des cassures fraîches. Parmi eux, trois formes très ouvertes (couvercles? assiettes?), de très bonne qualité, à surface brun foncé brillante (fig. $6, \mathrm{n}^{\text {os }} 14$, 15 et fig. $\left.18, n^{\circ} 12\right)$ sont couvertes de coups d'ongle, de technique proche du $\mathrm{n}^{\circ} 9$ de la figure 6 . Des bords ont des décors de cordons digités ou de coups d'ongle (fig. 7, $\mathrm{n}^{\text {os }} 1-11,14,18$ ); d'autres décors, cordons simples ou digités, pastillages, etc., ornent des fragments de panses (fig. $7, \mathrm{n}^{\text {os }} 12,13,15,16,23,24$, 27-29) ; leur disposition peut être orthogonale (fig. 7, $\left.\mathrm{n}^{\text {os }} 1,15\right)$. Ils gagnent parfois la bordure des fonds 

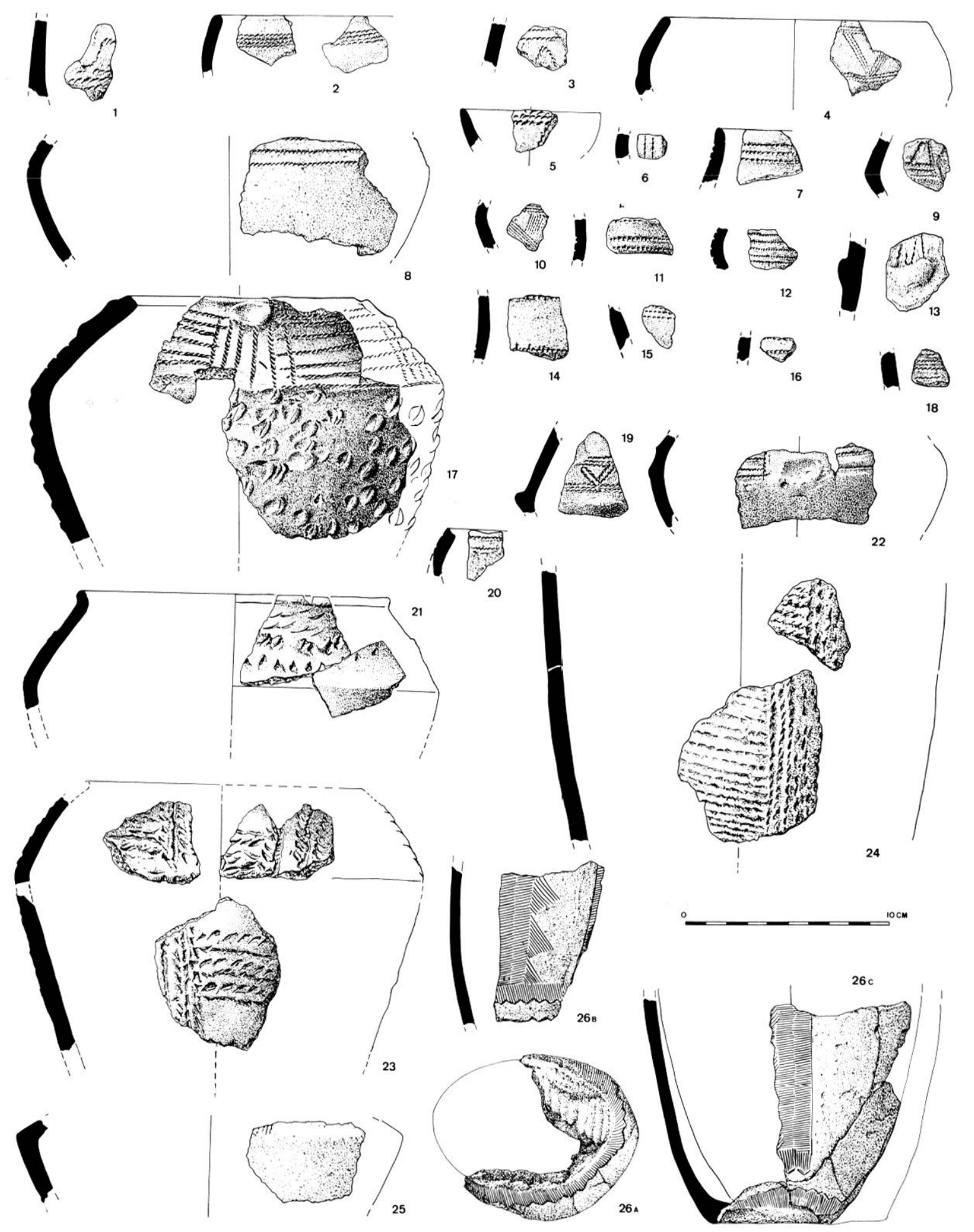

Fig. 5 - La Palut, céramique du Bronze ancien : 1-20, 22, 25, décors à la cordelette (17, décor mixte, cordelette et coups d'ongle); $21,23,24$, décors de coups d'ongle; 26 , vase ovale à décor d'incisions fines. 

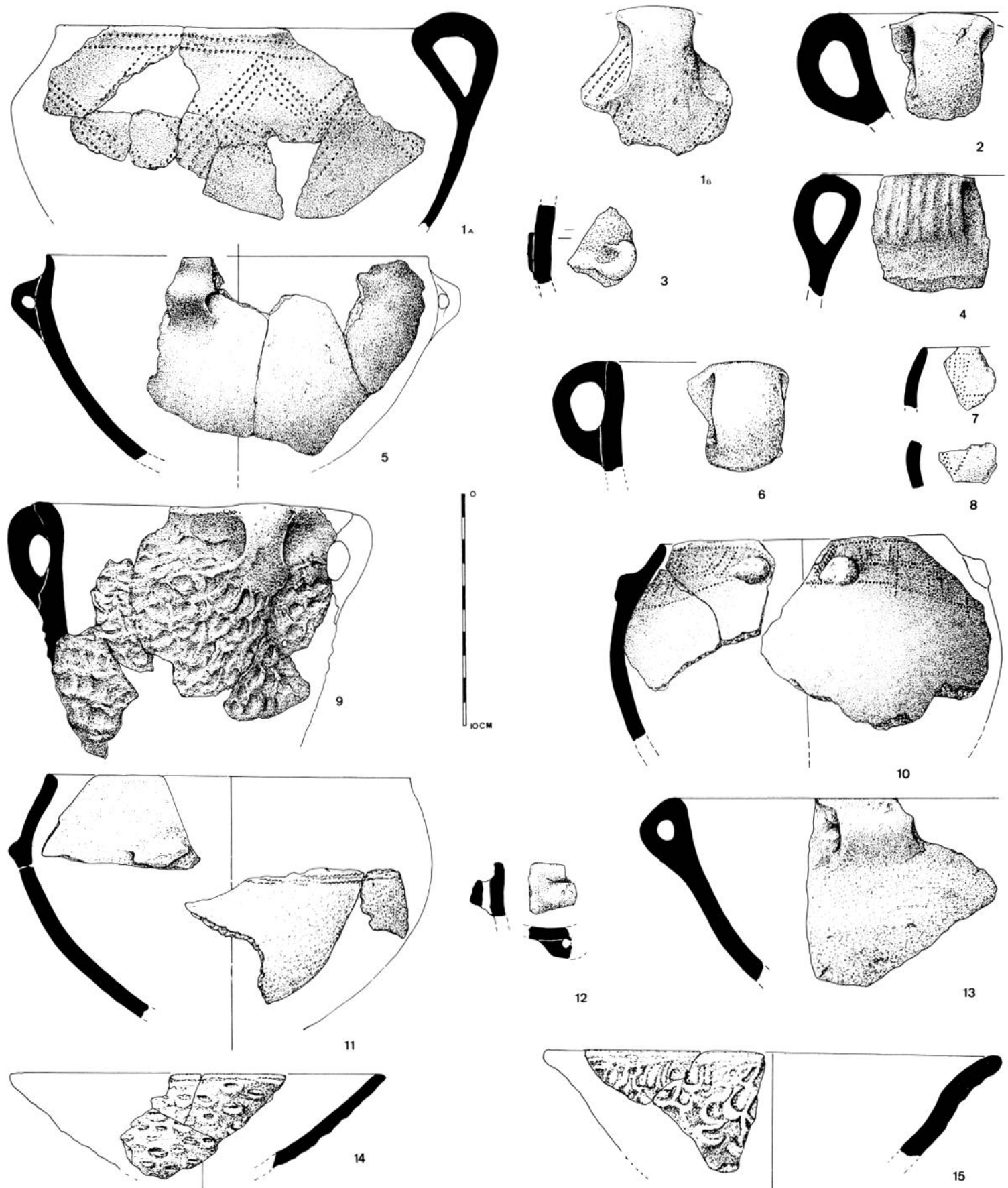

Fig. 6 - La Palut, céramique du Bronzc ancien : 1, vase à motif de grecques pointillécs, anse sur le bord ; 2, 4,6, 13, vases à anse sur le bord dont une cannelée (n⿳⺈ 4 ) ; 3 , fragment de décor en relief (pastille); 5 , vase ouvert à anse près du bord ; 7,8 , tessons à motifs pointillés proches du no $1 ; 9$, vase à anse sur le bord, décor de coups d'ongle; 10 , vase à boutons, décor de damiers pointillés; 11 , vase à décor de lignes pointillées; 12 , languette à perforation verticale; 14, 15, vases ouverts à décor de coups d'ongle.

(fig. $7, \mathrm{n}^{\text {os }} 17,19,20,22,25$ ) ou occupent même la surface de ceux-ci, faisant penser qu'il peut s'agir en réalité de couvercles (fig. $7, \mathrm{n}^{\text {os }} 26,28$ ).

Les cruches. Elles sont relativement bien représentées, avec des exemplaires décorés ou non (fig. 8, $n^{\text {os }} 1-5$ et fig. $18, n^{\text {os }} 1,8$ ). La pâte est fine, lissée, bien cuite, souvent rougeâtre sauf le $\mathrm{n}^{\circ} 2$ qui est noir. Elles ont en commun une forme élancée, un col cylindrique et une anse en ruban s'attachant plus ou moins haut sous le bord. Leur décor consiste en lignes horizontales parallèles au sommet du col et de la panse (fig. $8, \mathrm{n}^{\circ} \mathrm{l}$ ), en hachures croisées sur l'anse 

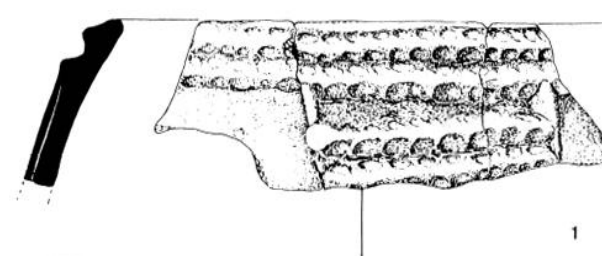

$\sqrt{v^{n} x^{2}}$

$$
10
$$

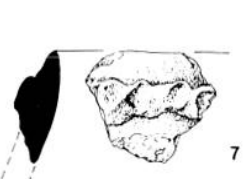

1

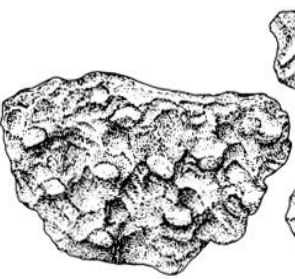

(5)

$$
1 \times \log ^{\circ}
$$
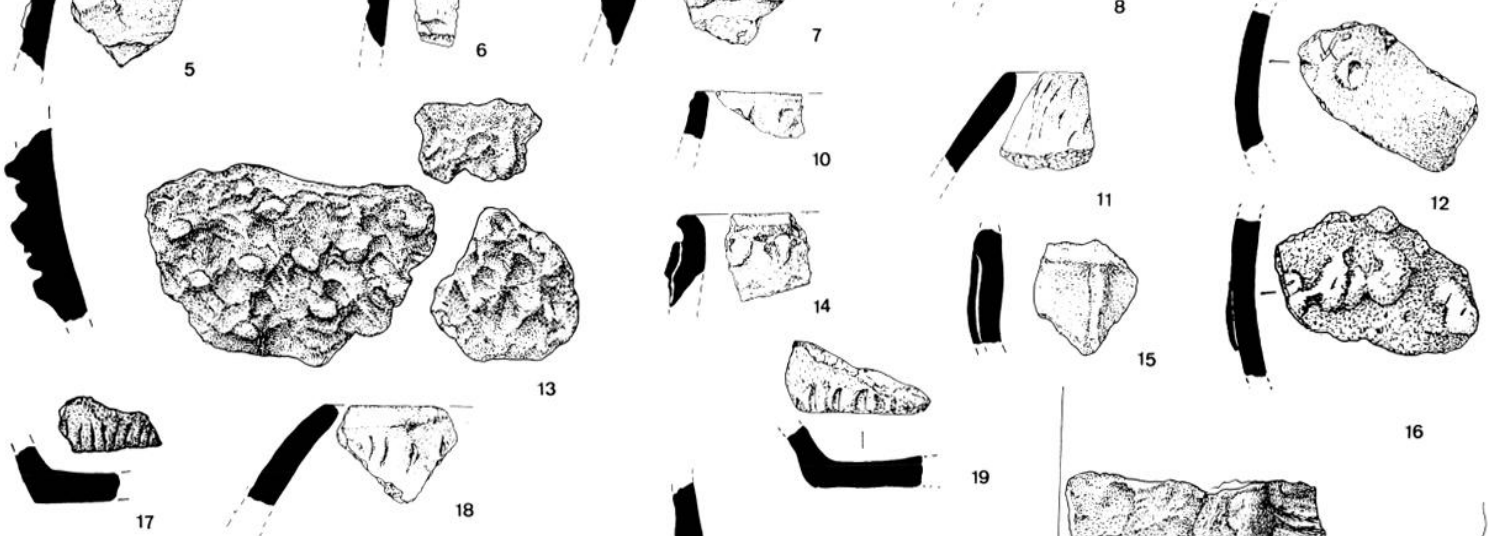

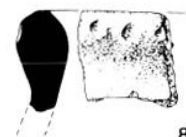

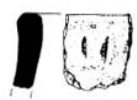




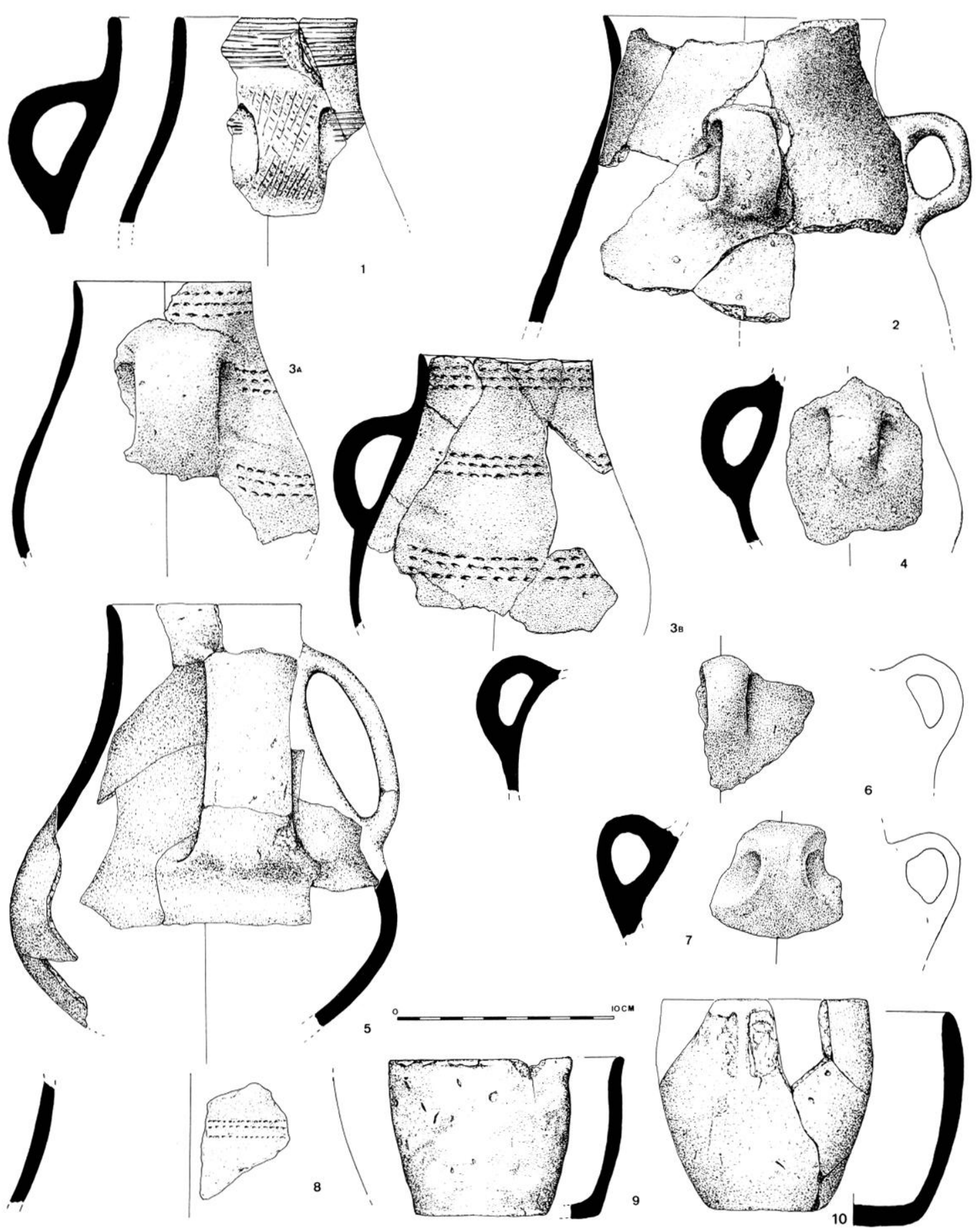

Fig. 8 - La Palut, céramique du Bronze ancien : $1-5$, cruches $; 6,7$, anses ; 8 , fragment de cruche (?) à décor pointillé ; 9, 10 , petits vases en pot de fleurs.

(fig. $8, \mathrm{n}^{\circ} 1$ ), en trois lignes à la corde sur l'anse (fig. 18, $\mathrm{n}^{\circ} 8$ ) ou en bandes horizontales de triples lignes de coups de poinçon, sous le bord et au niveau des attaches de l'anse (fig. $8, n^{\circ} 3 \mathrm{~A}, \mathrm{~B}$ ). Deux anses en ruban, moins hautes, pourraient provenir de cruches semblables (fig. $8, n^{\text {os }} 6,7$ ). Enfin, un fragment décoré d'une bande de trois lignes horizontales poinçonnées semble, par sa pâte et sa courbure, provenir d'un récipient du même type (fig. $8, \mathrm{n}^{\circ} 8$ ).

Deux petits pots de fleurs presque entiers (fig. 8 , $\left.\mathrm{n}^{\mathrm{os}} 9,10\right)$, dont l'un à moyen de préhension décollé $\left(n^{\circ} 10\right)$, sont de pâte plus grossière et moins bien cuite que les cruches. 


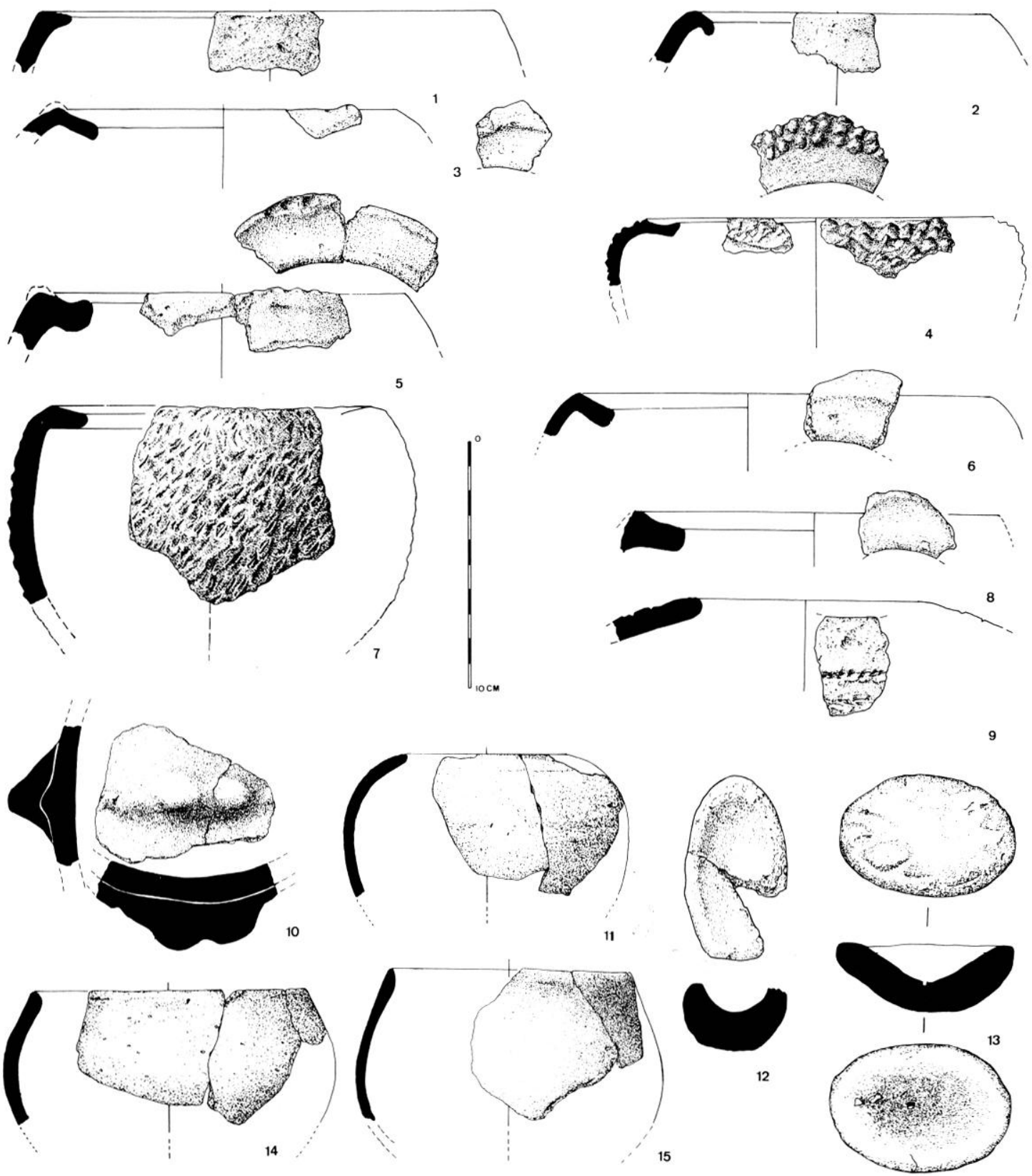

Fig. 9 - La Palut, céramique du Bronze ancien : 1-8, vases à collerette interne; $9,11,14,15$, vases à bord rentrant; 10, bouton double; 12, 13, godets ovales, épais (creusets ou lampes?).

Les vases à rebord plat interne et plongeant (fig. 9, $\mathrm{n}^{\mathrm{os}} 1-8$ et fig. $\left.18, \mathrm{n}^{\mathrm{os}} 2,9\right)$. Ils sont représentés par des éléments malheureusement fragmentaires. L'étalement vers l'intérieur est soit à peine marqué (fig. 9, $\left.n^{0} 1\right)$, soit court et fortement recourbé vers l'intérieur (fig. $9, \mathrm{n}^{\circ} 2$ ), soit plus large et formant une collerette intérieure tantòt concave (fig. $9, \mathrm{n}^{\text {os }} 4,5$ ), tantòt plate (fig. 9, $\mathrm{n}^{\text {os }} 6-8$ et fig. $18, \mathrm{n}^{\text {os }} 2,9$ ). Ces récipients sont minces, à pâte fine très bien cuite, et le plus souvent noirs ou gris. Cette catégorie très particulière semble le plus souvent décorée. Le $n^{\circ} 4$ de la figure 9 porte un décor original de petites pastilles coniques en relief très serrées, et le $\mathrm{n}^{\prime \prime} 7$ de la figure 9 et le $n^{\circ} 9$ de la figure 18 , des coups d'ongle juxtaposés, rappelant des décors précédemment rencontrés sur d'autres formes de vases; les $n^{\text {os }} 5$ et 8 de la figure 9 ont, sur le bord externe de la collerette, de légères protubérances décoratives; celle $d u n^{\prime \prime} 5$ est digitée; enfin le $n^{\circ} 9$ de la figure 18 est agrémenté d'une languette appliquée purement décorative.

Les vases à bord très rentrant sans collerette (fig. 9, $n^{\text {os }} 9,11$ et fig. $\left.18, n^{\circ} 10\right)$. Ils sont plus rares; l'un 

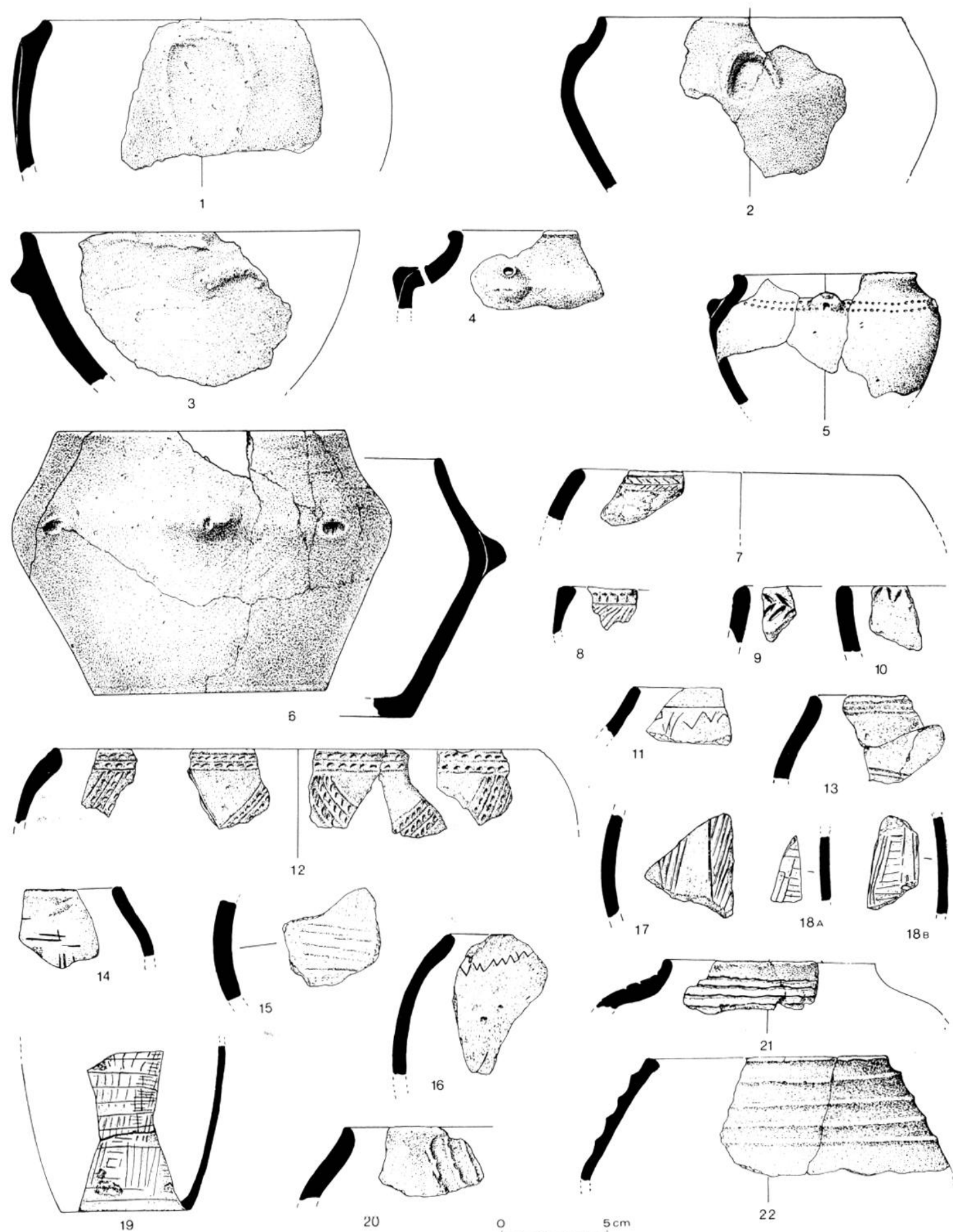

20
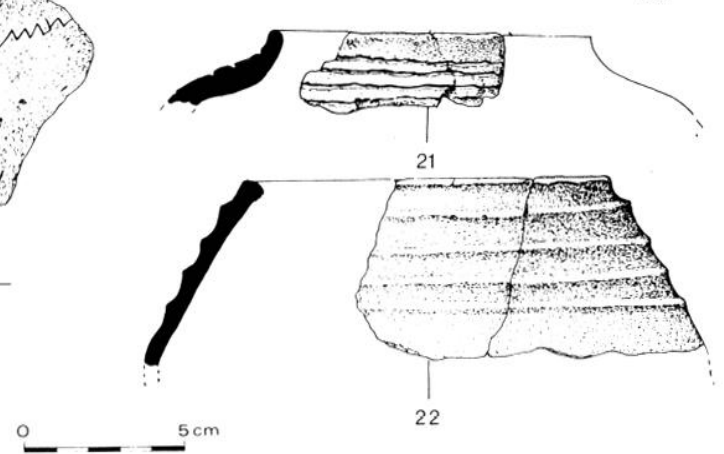

Fig. 10 - La Palut, céramique du Bronze ancien : 1-3, vases à cordon arciforme; 4, vase à paroi perforée au-dessus d'un bouton ; 5 , vase à bouton perforé verticalement; 6 , vase biconique à cupules ; 7-19, décors incisés et poinçonnés; 20 , décor de nervures en relief ; 21 , vase à lignes parallèles incisées; 22 , vase à légères cannelures.

(fig. 9, $\left.\mathrm{n}^{\circ} 11\right)$ est très proche des précédents par sa couleur noire et son excellente facture et l'autre (fig. 9, $\mathrm{n}^{\circ} 9$ ) montre un décor peu lisible; le $\mathrm{n}^{\circ} 10 \mathrm{de}$ la figure 18 possède un fond aplati.

Les écuelles à bord légèrement rentrant (fig. 9, $\left.\mathrm{n}^{\text {os }} 14,15\right)$. Cette forme est moins caractéristique.

Deux récipients peu profonds de contour ovale, épais et grossiers, très cuits, rougeâtres, restent d'une utilisation hypothétique (fig. 9, $\mathrm{n}^{\text {os }} 12,13$ ). L'un d'eux présente en son milieu un petit trou borgne, carré. Il pourrait s'agir de creusets ou de lampes, mais ils ne portent pas de traces visibles de scories ou de combustion.

Le cordon en fer à cheval simple (fig. 10, $\mathrm{n}^{\text {os }} 1-3$ et 

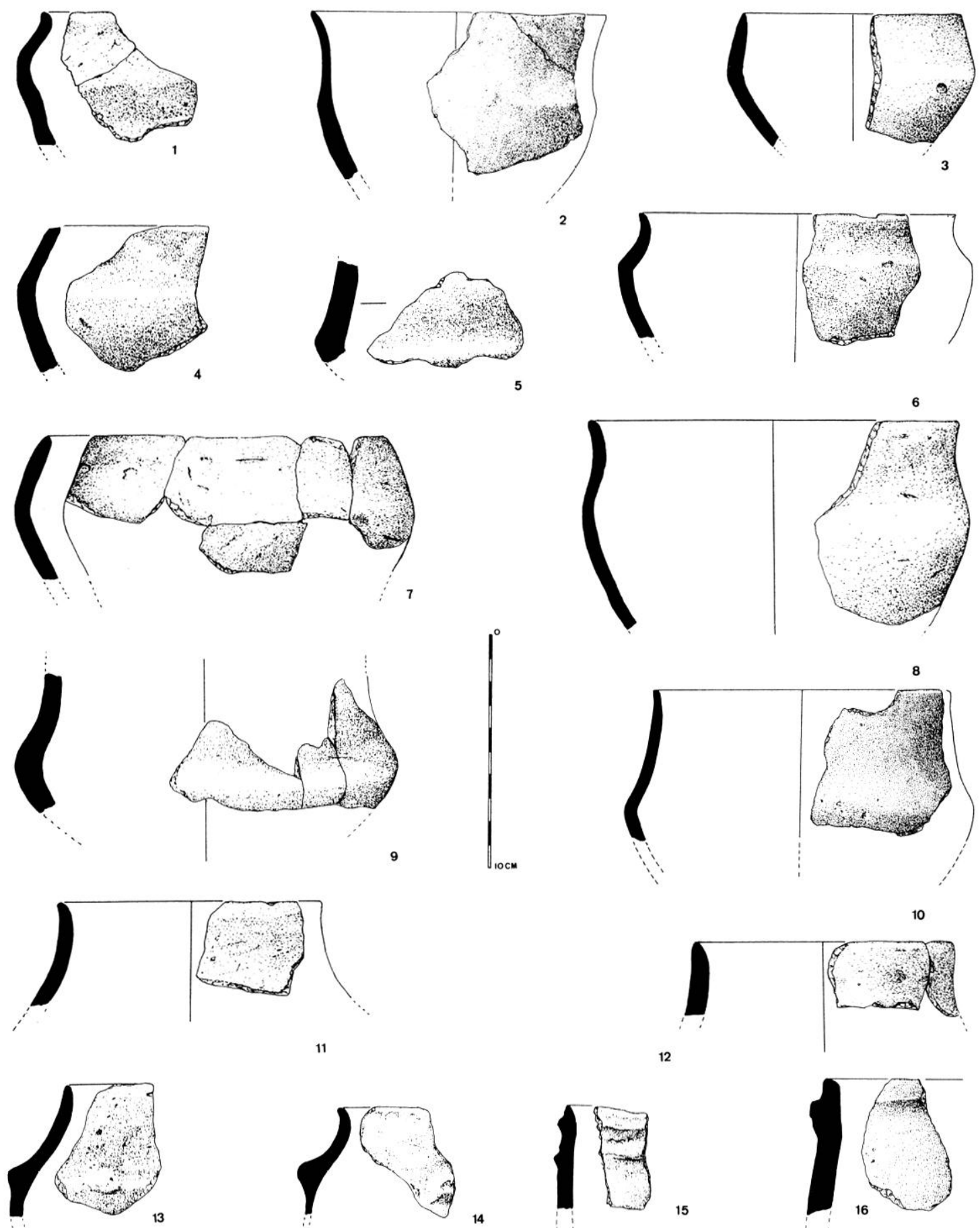

Fig. 11 - La Palut, céramique du Bronze ancien : 1-10, vases carénés; 11-14, vases à col; 15, 16, cordons simples horizontaux. 

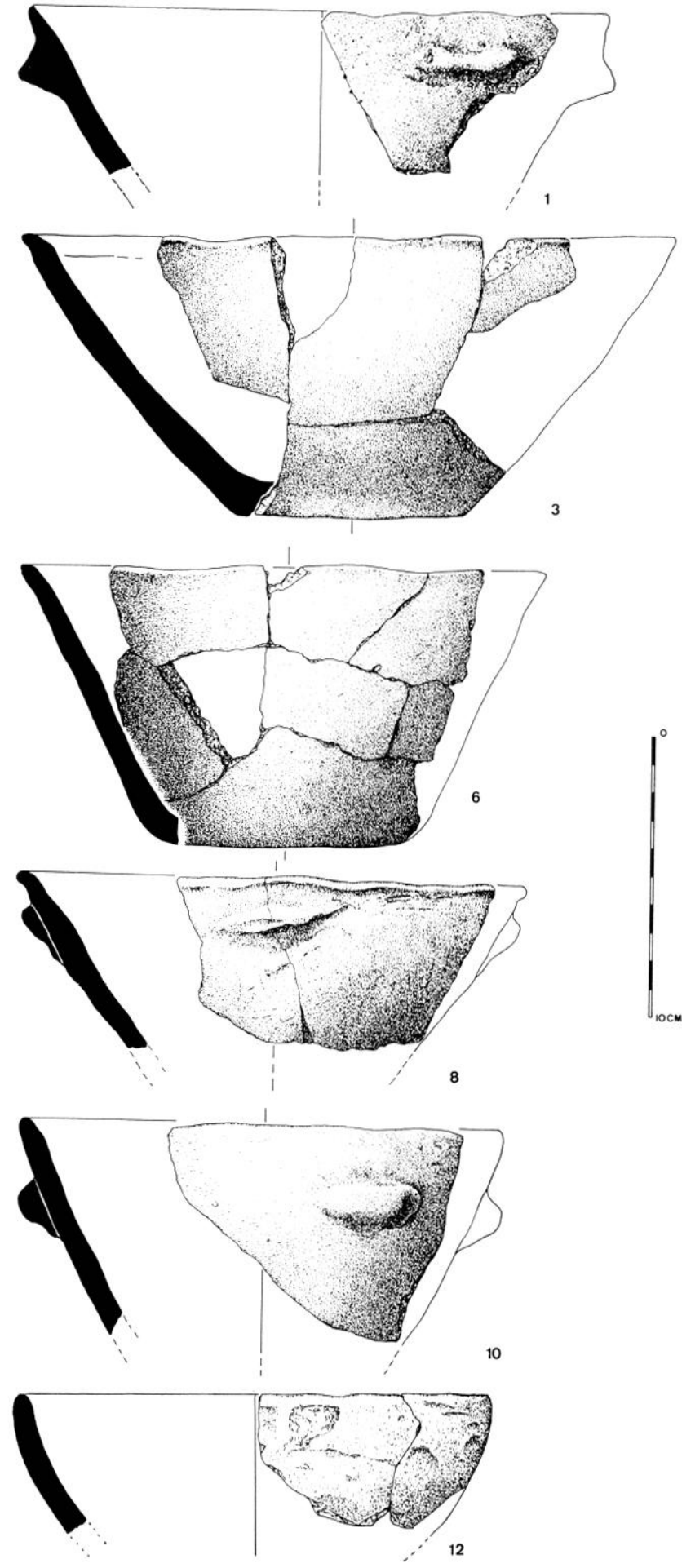
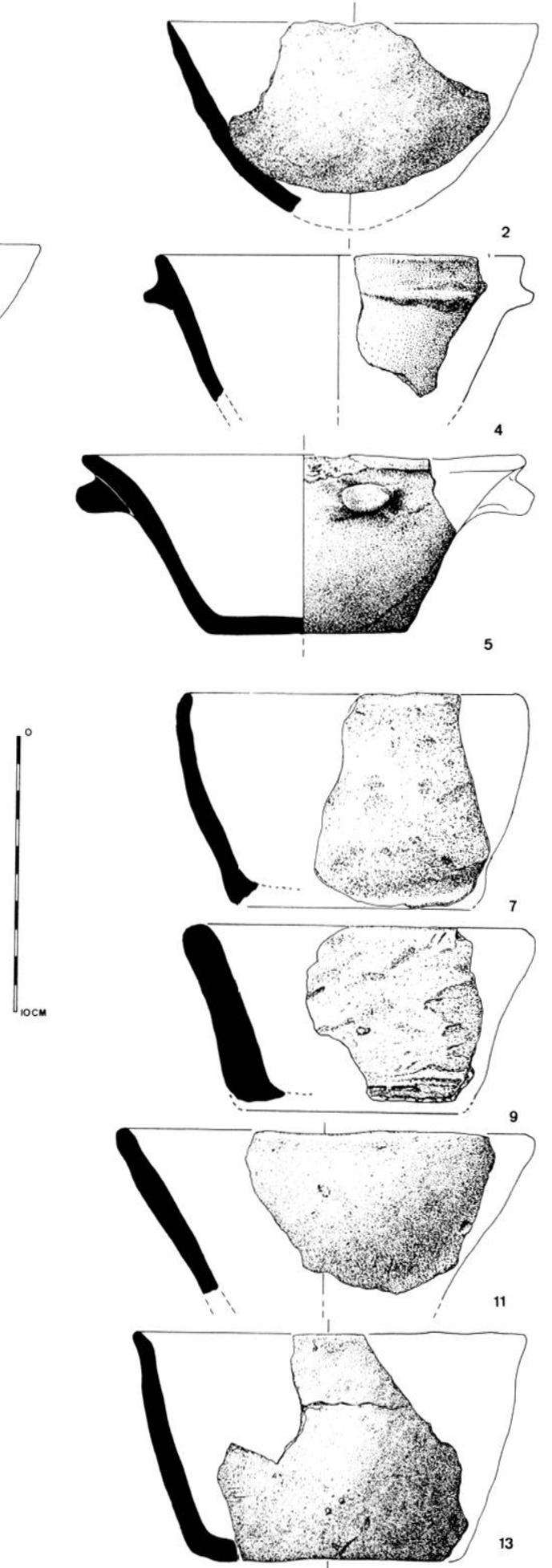

Fig. 12 - La Palut, céramique du Bronze ancien : 1-13, vases tronconiques bas. 

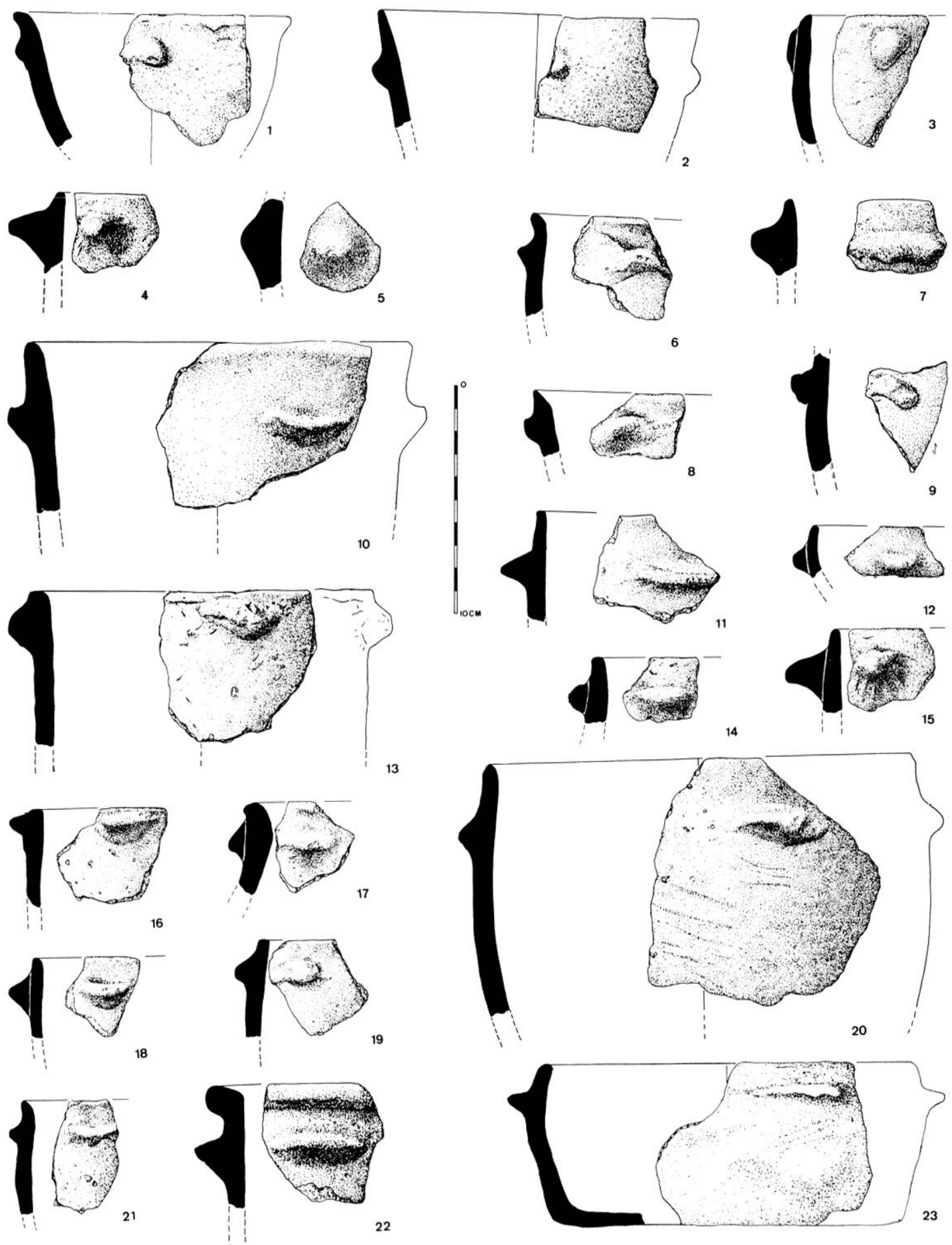

Fig. 13 - La Palut, céramique du Bronze ancien : 1-23, vases à paroi éversée ou droite, à boutons ou languettes de préhension. 

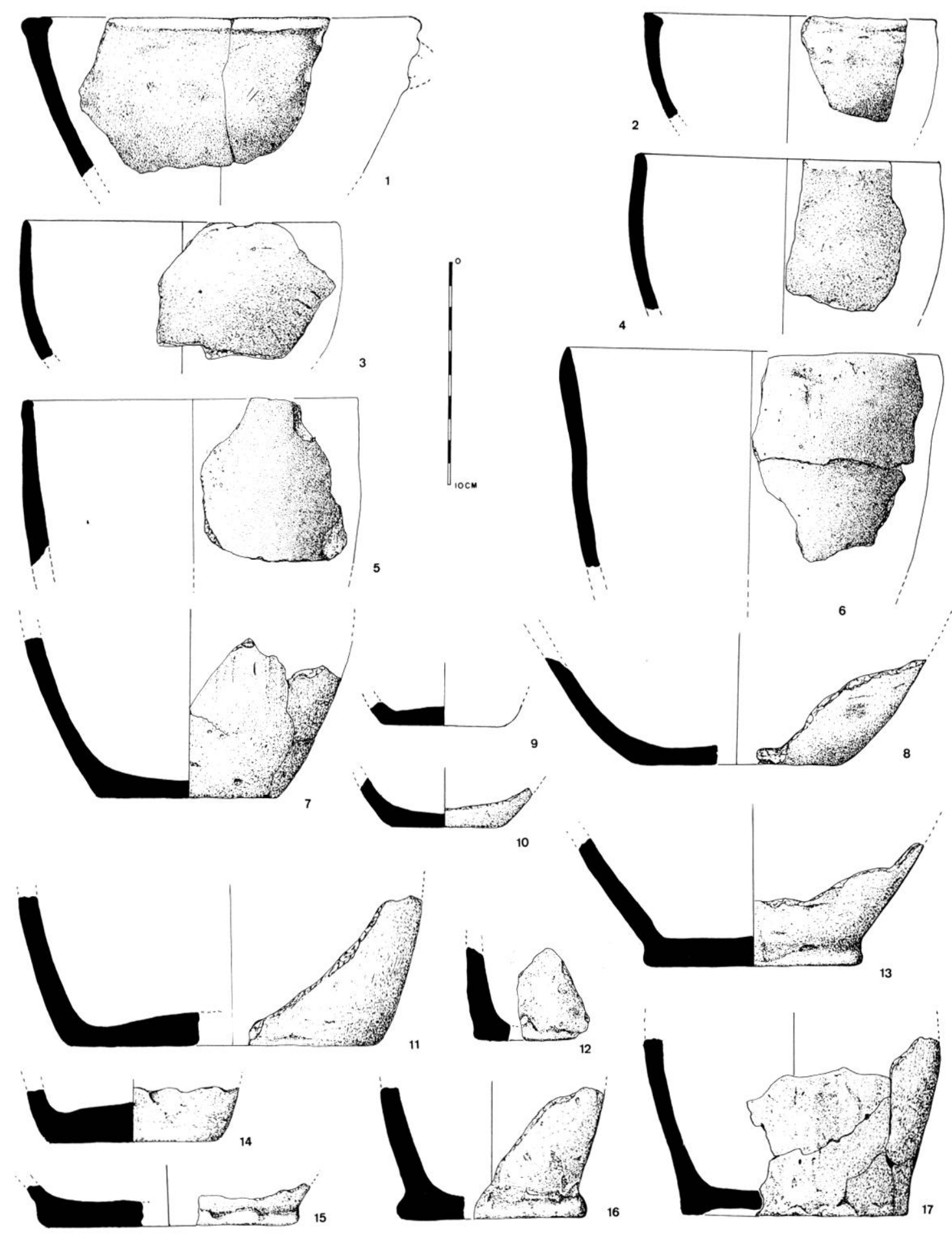

Fig. 14 - La Palut, céramique du Bronze ancien : 1-6, vases non décorés de forme ouverte; $7-17$, fonds plats. 

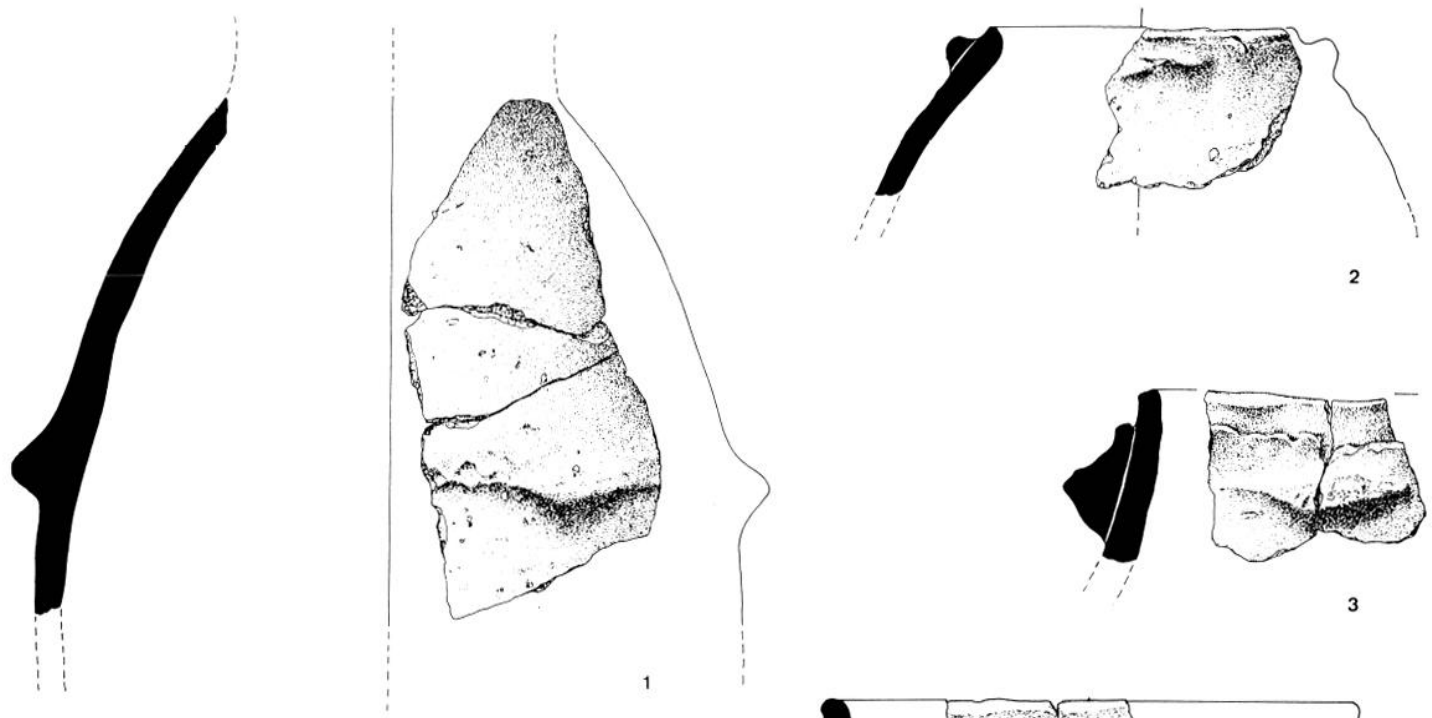

2
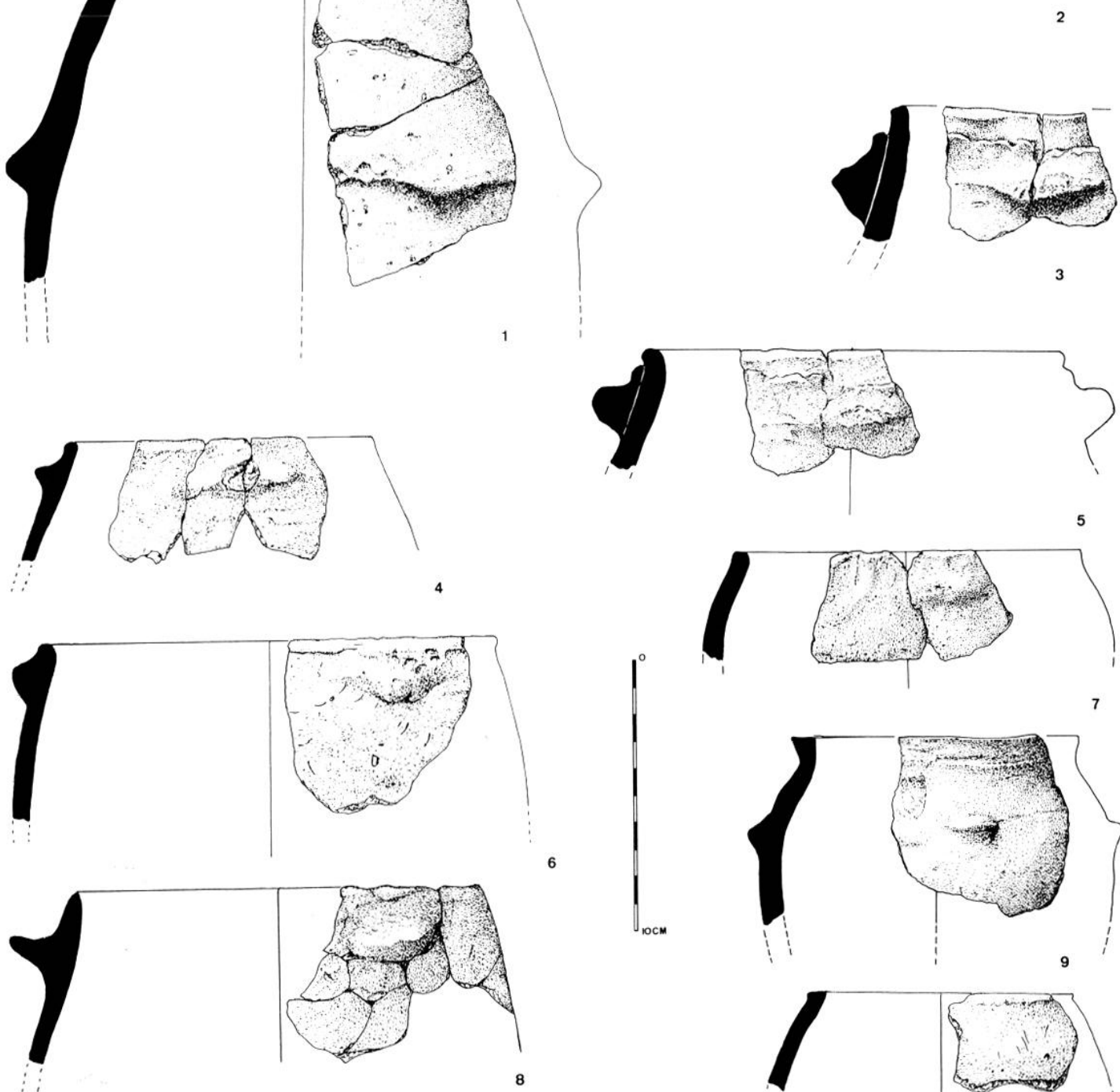

6
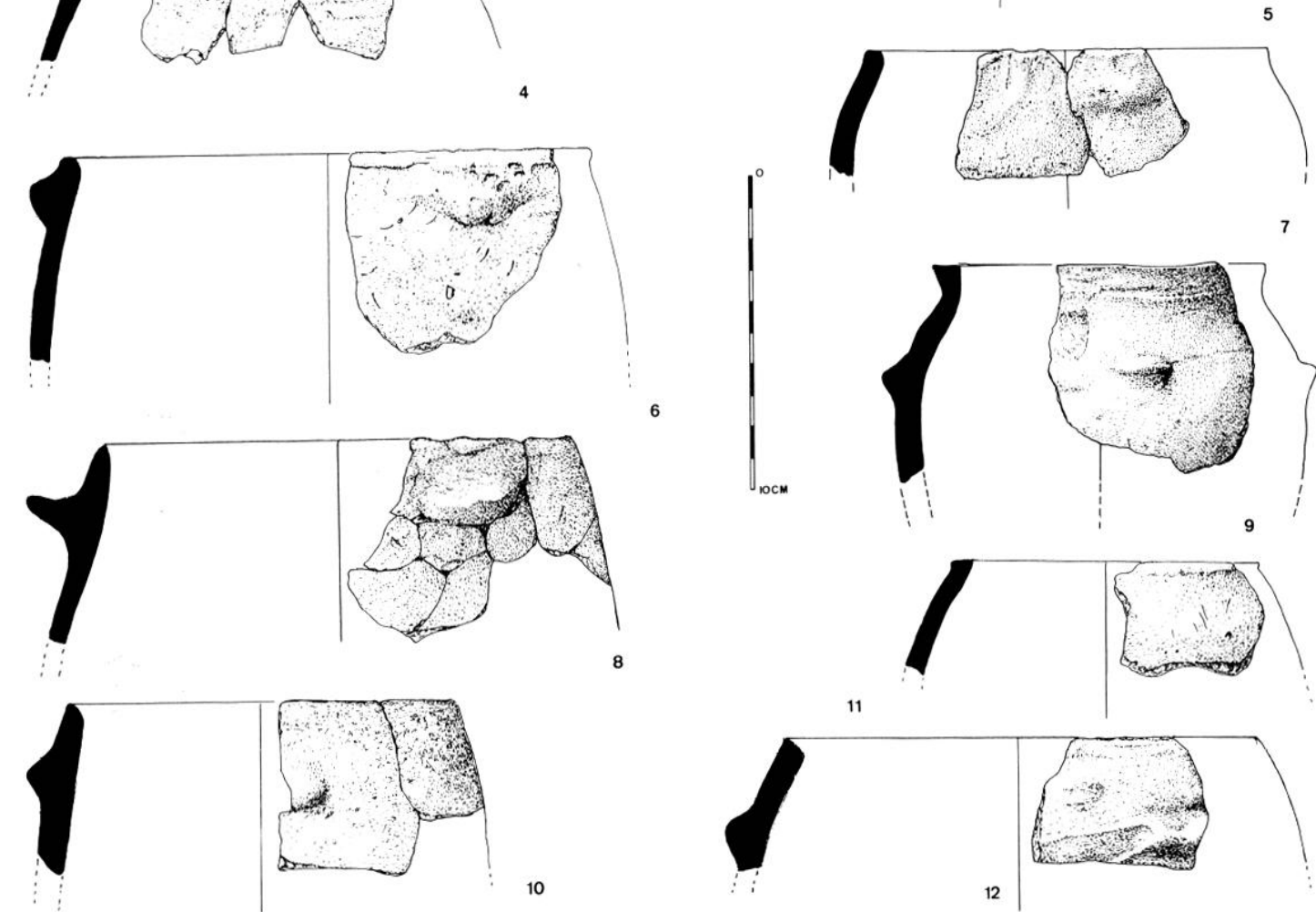

11

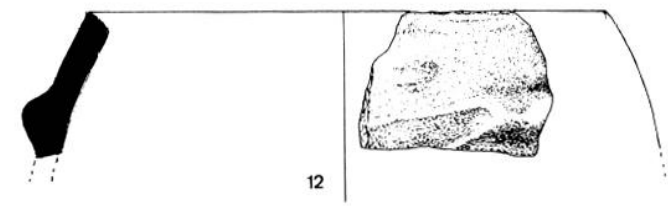

Fig. 15 - La Palut, céramique du Bronze ancien : 1-12, vases non décorés, de forme fermée, à boutons ou languettes de préhension. 

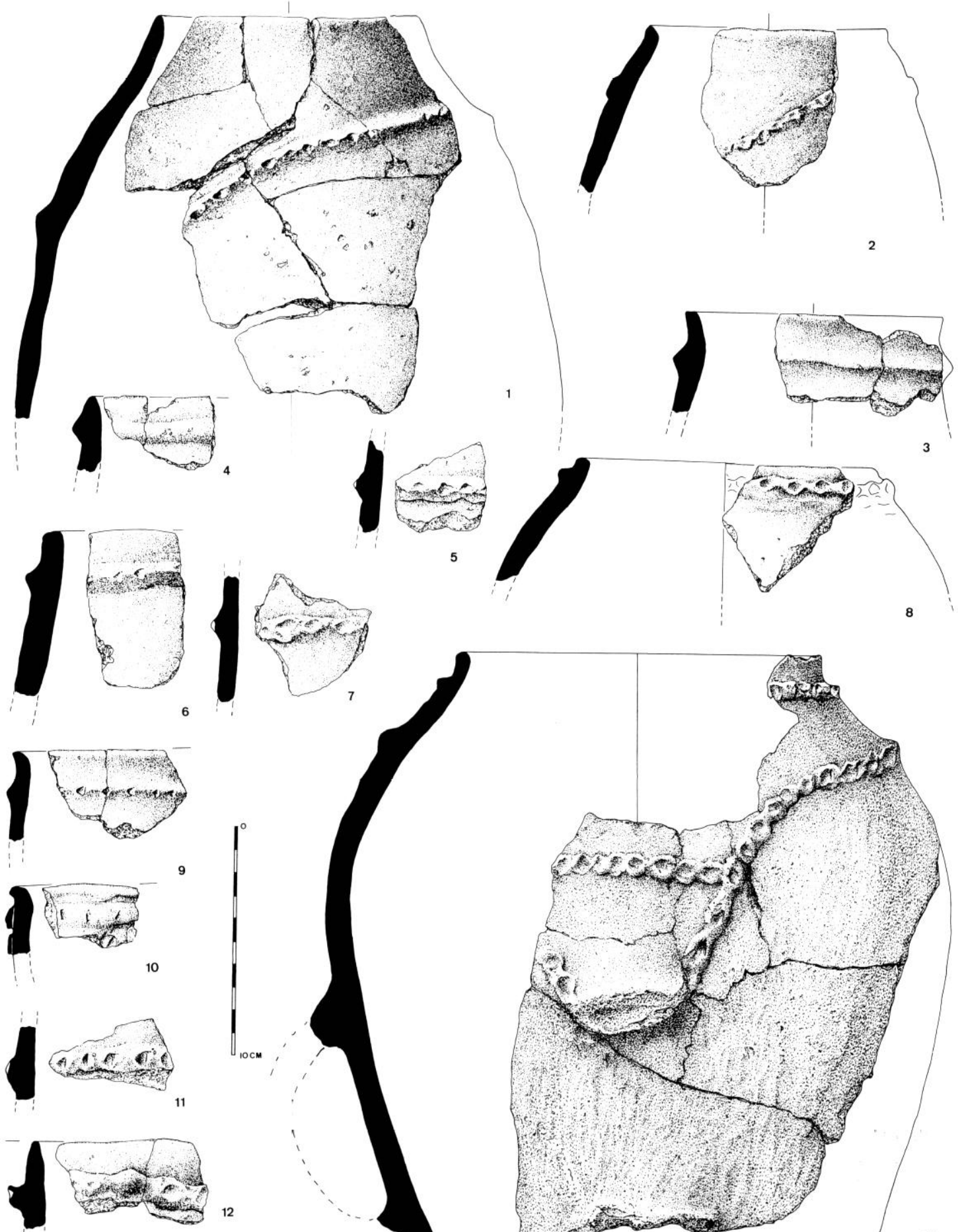
fig. $\left.18, n^{\circ} 5,7\right)$ est présent sur des vases de formes différentes : une écuelle à bord rentrant (fig. $10, \mathrm{n}^{\circ} 1$ ) porte un relief arciforme peu saillant, mais très refermé vers le bas; une écuelle à épaulement (fig. 10, $\mathrm{n}^{\mathrm{0}}$ 2), à col rentrant et bord légèrement éversé, porte sur l'épaule un petit fer à cheval en relief plus marqué que le précédent; un bol (fig. 10, $n^{\circ} 3$ ) possède une prise légèrement arquée; une autre est placée très haut sur un col paraissant cylindrique. Rappelons enfin que, sur l'exemplaire à rebord rentrant $n^{\circ} 7$ de la figure 18 , on distingue les vestiges d'un décor à la cordelette.

Deux petits vases à épaulement haut (fig. $10, \mathrm{n}^{\text {os }} 4$, 5 ) sont de forme très proche $d u n^{\circ} 2$, avec un col concave, court, rentrant, et un bord éversé et roulé. Ils portent de curieux moyens de préhension : dans le premier cas, une perforation cylindrique, faite avant cuisson, traverse la paroi au sommet d'un mamelon placé sur l'épaulement; le second présentait, à hauteur de l'épaulement, de petits boutons à perforation verticale étroite, probablement au nombre de quatre, joints par un décor de deux lignes horizontales poinçonnées.

Un vase à fond plat à épaulement plus bas (fig. 10 , $\mathrm{n}^{0} 6$ ), de fabrication très soignée, bien cuit, est presque entier et montre, à hauteur du plus grand diamètre, deux dépressions ovales encadrant une languette horizontale à incision médiane. On peut se demander si ces dépressions ornementales n'ont pas été prévues à l'origine pour recevoir des incrustations.

De nombreux tessons décorés attestent l'existence d'une série de vases dont la forme complète ne peut pas toujours être reconstituée. D'après les bords, on peut reconnaître des formes ouvertes (fig. $10, n^{\text {os }} 9$, 10 ) et de plus nombreuses formes fermées $\left(n^{\text {os }} 7,11\right.$ 16, 21, 22). Plusieurs type de décors se distinguent selon la technique employée et l'organisation des motifs : cannelures étroites $(n * 13,22)$, incisions fines $\left(\mathrm{n}^{\mathrm{os}} 7,8,11,15-19\right)$, impressions ovales ( $\mathrm{n}^{\text {os }} 9$, 10 ), combinaison d'incisions et de poinçonné ( $\left.n^{\circ} 12\right)$, lignes en relief $\left(n^{\circ} 20\right)$. Les motifs ainsi obtenus sont variés: lignes horizontales groupées $\left(n^{* 8} 13,21\right)$, arêtes de poisson $\left(n^{\circ} 7\right)$, échelles et hachures obliques ( $\left.n^{\circ} 8\right)$, chevrons emboîtés ( $\left.n^{\circ} 9\right)$ ou juxtaposés ( $\left.n^{\circ} 10\right)$, zigzags ( $\left.n^{\circ} 11,16\right)$, triangles hachurés ( $\left.n^{\circ} 17\right)$. On remarque plusieurs fragments, malheureusement non coaptables, d'un même vase légèrement refermé, à bandes poinconnées en chevrons, sous une ligne d'appui qui souligne le bord $\left(n^{\circ} 12\right)$. Un petit vase à fond plat, dont la partie supérieure manque, porte un décor couvrant de hachures alternativement verticales, horizontales ou croisées, dont l'organisation d'ensemble nous échappe ( $\left.n^{\circ} 19\right)$; trois autres fragments de vases différents sont très proches par leur décor ( $\left.\mathrm{n}^{\text {os }} 14,15,18\right)$. Le fragment $n^{\circ} 20$, que dans un autre contexte on aurait attribué au style de Kérugou, et le $\mathrm{n}^{0} 21$, à incisions horizontales parallèles, détonnent quelque peu dans cet ensemble.

Les vases carénés (fig. 11, $\mathrm{n}^{\mathrm{os}} \mathrm{1}-10$ ) ont des profils assez variés dans le détail. Les carènes sont, soit plutôt hautes ( $\left.{ }^{\text {os }} 1,4,6\right)$, soit médianes $\left(n^{\text {os }} 2,3,7\right)$, soit même assez basses $\left(n^{\text {os }} 5,9,10\right)$. Le profil de la partie supérieure peut être concave ( $\left.\mathrm{n}^{\text {os }} 2,5,6,8-10\right)$ ou droit ( $\left.\mathrm{n}^{\text {ss }} 3,4,7\right)$. Aucun fond n'a pu leur être raccordé et aucun d'entre eux n'est décoré.

Les vases à col (fig. $\left.11, \mathrm{n}^{\text {os }} 11,12\right)$ sont connus par divers fragments; certains, portant des boutons ou languettes, pourraient aussi bien appartenir au groupe précédent ( $\left.{ }^{\text {os }} 13,14\right)$.

Les petites jattes tronconiques à fond plat ou plus rarement arrondi (fig. $12, \mathrm{n}^{\text {os }} 1-13$ ) sont représentées par une bonne série; elles sont généralement de facture médiocre. Certaines ont des moyens de préhension, languettes horizontales plus ou moins allongées $\left(\mathrm{n}^{0 \mathrm{~s}} 1,4,8,10\right)$ ou plus rarement bouton saillant $\left(n^{\circ} 5\right)$. Des formes voisines sont attestées par de nombreux fragments à boutons ou languettes horizontales (fig. 13, $\mathrm{n}^{\text {os }} 1,2$ ).

Les vases subcylindriques et globuleux sont également munis de boutons ou languettes, souvent proches du bord, et sont représentés par des fragments qui ne permettent pas toujours une reconstitution d'ensemble (fig. 13, $n^{* * 10-23) . ~ O n ~}$ notera la forme large et basse de l'un des exemplaires les plus complets (fig. $13, \mathrm{n}^{\circ} 23$ ), le rebord à renforcement externe du $n^{\circ} 22$ et le rebord plat, débordant à l'intérieur comme à l'extérieur, du $n^{\circ} 1$ de la figure 14 qui devait porter une anse. On y ajoutera des vases de forme analogue mais dépourvus de moyens de préhension, du moins sur les parties conservées (fig. 14, $\mathrm{n}^{\circ}$ 2-6). Des fonds plats, ayant probablement appartenu à des récipients de ces types. sont d'une grande variété dans le détail : les uns sont simplement aplatis $\left(n^{o s} 7,8,10\right)$, parfois légèrement plus épais au centre $\left(n^{\circ s} 9,11,14\right)$, les autres plus épais et débordants ( $\left.n^{\text {os }} 12,13,15,16\right)$. On remarque un fond annulaire peu élevé ( $\left.n^{\circ} 17\right)$.

Les vases de formes plutôt fermées (fig. 15) constituent une abondante série de pots assez grossiers, mème quand ils n'ont qu'une taille moyenne. Ils portent souvent des moyens de préhension, surtout des languettes horizontales de facture assez négligée, proches du bord, disposées parfois sur de 


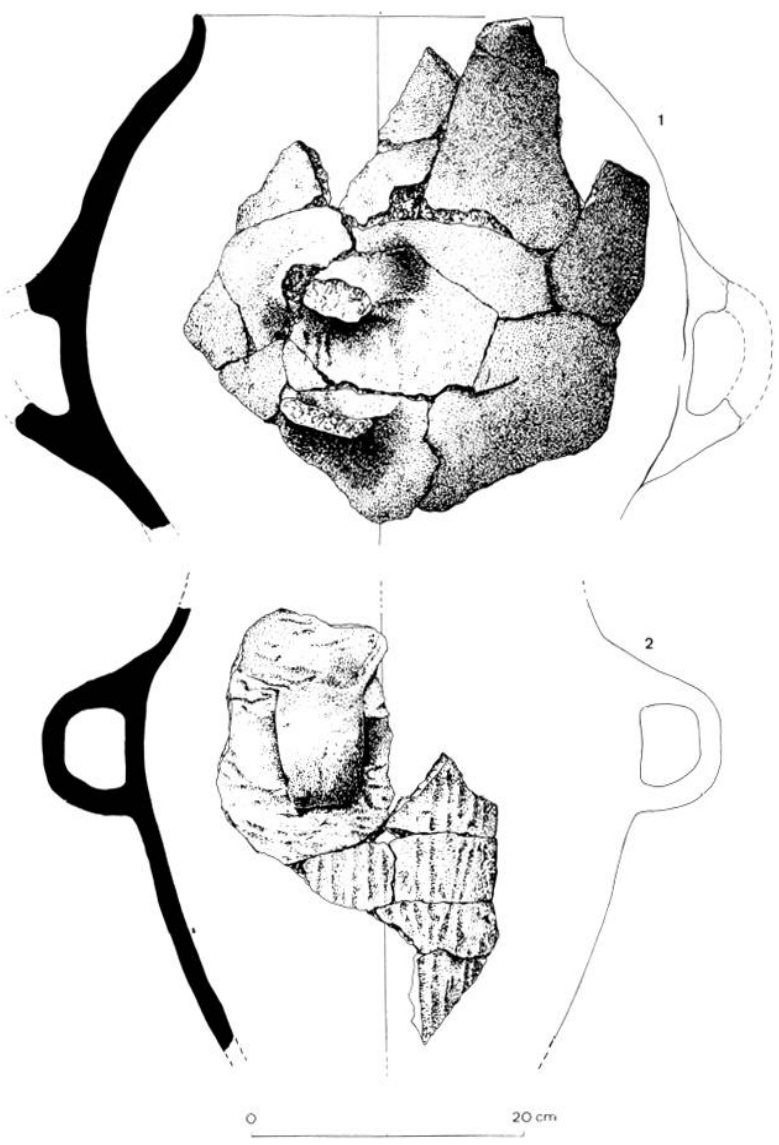

Fig. 17 - La Palut, céramique du Bronze ancien: 1, 2, grandes jarres à anses.

grossiers cordons $\left(\mathrm{n}^{\circ \mathrm{s}} 3,5\right)$. Les boutons ne sont cependant pas absents ( $\left.n^{\circ} 10\right)$.

Les grands vases à provisions (fig. 15, $\mathrm{n}^{\circ} 1$; fig. 16 ; fig. 17 et fig. $18, \mathrm{n}^{\text {os }} 11,13$ ) sont certainement sous-représentés ici, vu les difficultés de remontage; ils devaient être abondants. On y reconnaît des jarres en tonnelet dont certaines à bord très refermé (fig. $15, \mathrm{n}^{\circ} 1$; fig. 16, $\mathrm{n}^{\mathrm{os}} 1,8,13$ et fig. 18, $\mathrm{n}^{\circ} 13$ ). Parmi les moyens de préhension, on note une languette sur cordon (fig. $15, n^{\circ} 1$ ) et de grosses anses en ruban (fig. $16, n^{\circ} 13$ et fig. 17, $n^{\text {os }} 1$, 2), parfois placées assez bas. Ces vases ont souvent des cordons digités, ou plus rarement simples. Certains, horizontaux, soulignent souvent le bord (fig. $16, \mathrm{n}^{\mathrm{os}} 3,4,6,8-10,12,13$ ), d'autres partent en oblique et devaient faire partie de compositions plus complexes (fig. 16, $n^{o s} 1,2$ ). L'anse du vase $n^{\circ} 13$ de la figure 16 est encadrée de cordons digités dont la disposition évoque celle que pouvaient avoir des cordes de transport pour ces grands vases.

\section{La céramique de l'Âge du Fer}

Beaucoup moins abondante sur le site - où elle avait, rappelons-le, une distribution différente de celles des époques précédentes - la céramique de l'Âge du Fer (fig. 19) s'en distingue aisément, tant par les formes que par la technique de fabrication et la cuisson; certains vases sont faits au tour. On y reconnaitra, pour l'essentiel, des vestiges d'une occupation attribuable à La Tène III.

\section{AUTRES SITES DU BRONZE ANCIEN DE LA VALLEE DE LA SEUGNE}

La découverte de cet ensemble original de céramiques de La Palut nous a servi de fil conducteur pour regrouper d'autres trouvailles récentes. Un bon nombre de ces sites ont été récemment découverts par J.-M. Bouchet au cours de prospections systématiques dans le même secteur, tant dans les milieux humides que sur les hauteurs. Les vestiges, moins abondants sans doute qu'à La Palut, sont cependant typiques.

\section{Les Orgeries A Courcoury (Charente-Maritime)}

Le tamisage de déblais d'un curage ancien de la Seugne nous a révélé des vestiges du Cardial, du PeuRichard, de l'Artenacien, un tesson campaniforme et. de la céramique du Bronze ancien : tessons décorés à la cordelette dont un bord et un fragment de vase biconique (fig. 20, $\mathrm{n}^{\text {os }} 2-5$ ), décor de coups d'ongle probablement aussi sur un vase biconique ( $n^{0} 6$ ), fragments de plusieurs vases à impressions d'ongle parfois combinées à des incisions ( $\left.\mathrm{n}^{\text {os }} 7-10\right)$. On y ajoutera peut-être, par comparaison avec des éléments semblables de La Palut, un fragment de couvercle tronconique dont la partie plate porte des pustules ( $\left.n^{\circ} 1\right)$.

\section{Diconche à Saintes (Chahen'te-Maritime)}

Le sauvetage d'enceintes à occupations multiples a permis de récupérer, en position stratigraphique sur les fossés, des témoins du Campaniforme et du Bronze ancien. Citons, entre autres, des vases tronconiques décorés de coups d'ongle, des cordons digités en relation ou non avec des bords et/ou des moyens de préhension, des décors incisés et un décor à pastilles identique à celui de La Palut (fig. 9, $n^{\circ} 4$ ). Il faut souligner la présence d'une épingle en os à tête plate, en rame, à large perforation. 

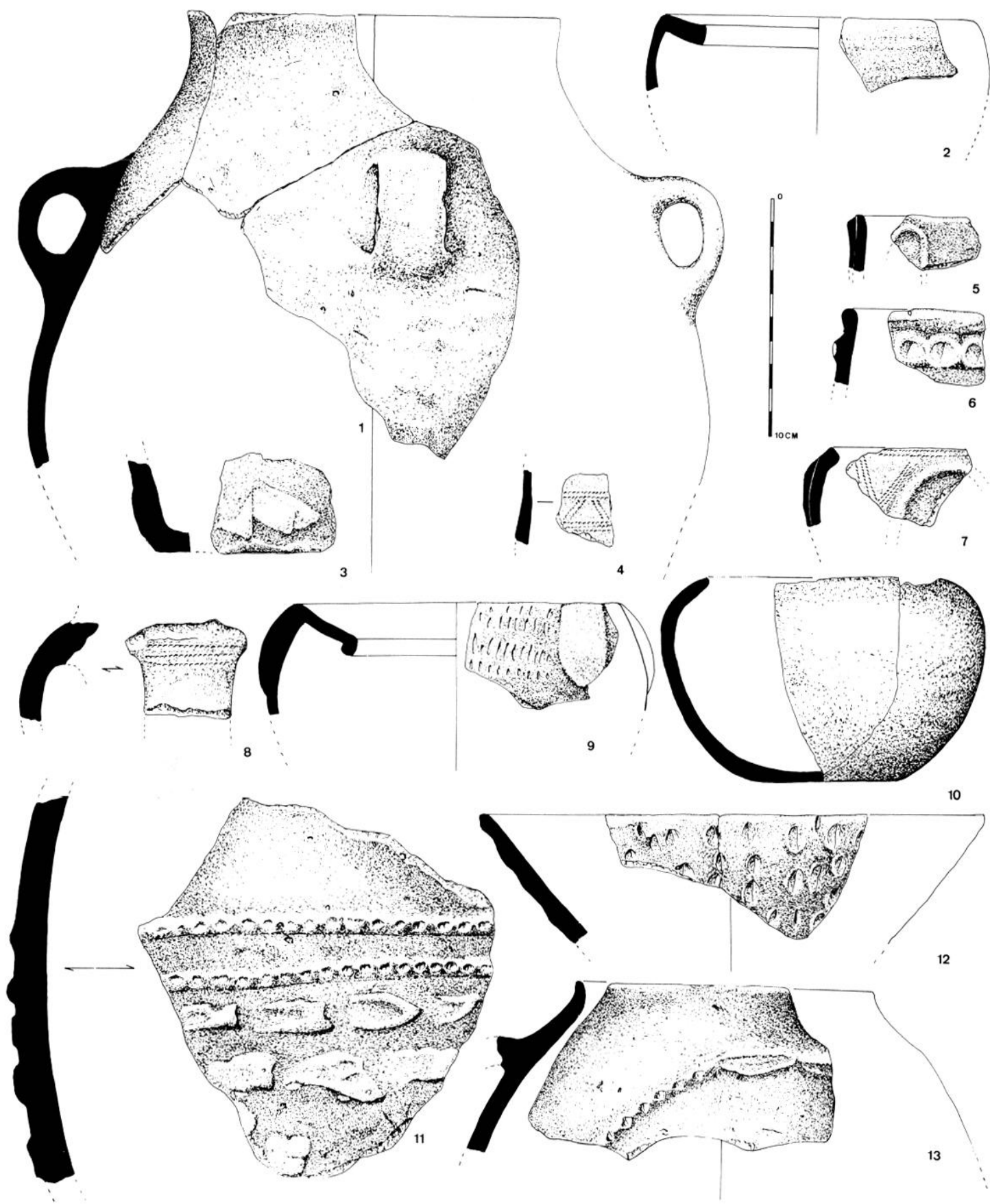

Fig. 18 - La Palut, céramique du Bronze ancien provenant du sondage de $1988: 1$, grande cruche $; 2,9$, vases à collerette interne $; 3$, pastillages près d'un fond plat; $4,7,8$, décors à la cordelette (associés à l'arceau en relief sur le vase à bord rétréci no 7 ); 5 , fin cordon en arceau près d'un bord; 6 , cordon digité sous un bord; 10 , vase à bord rétréci comme le $\mathrm{n}^{\circ} 7 ; 11-13$, vases à décor plastique. 


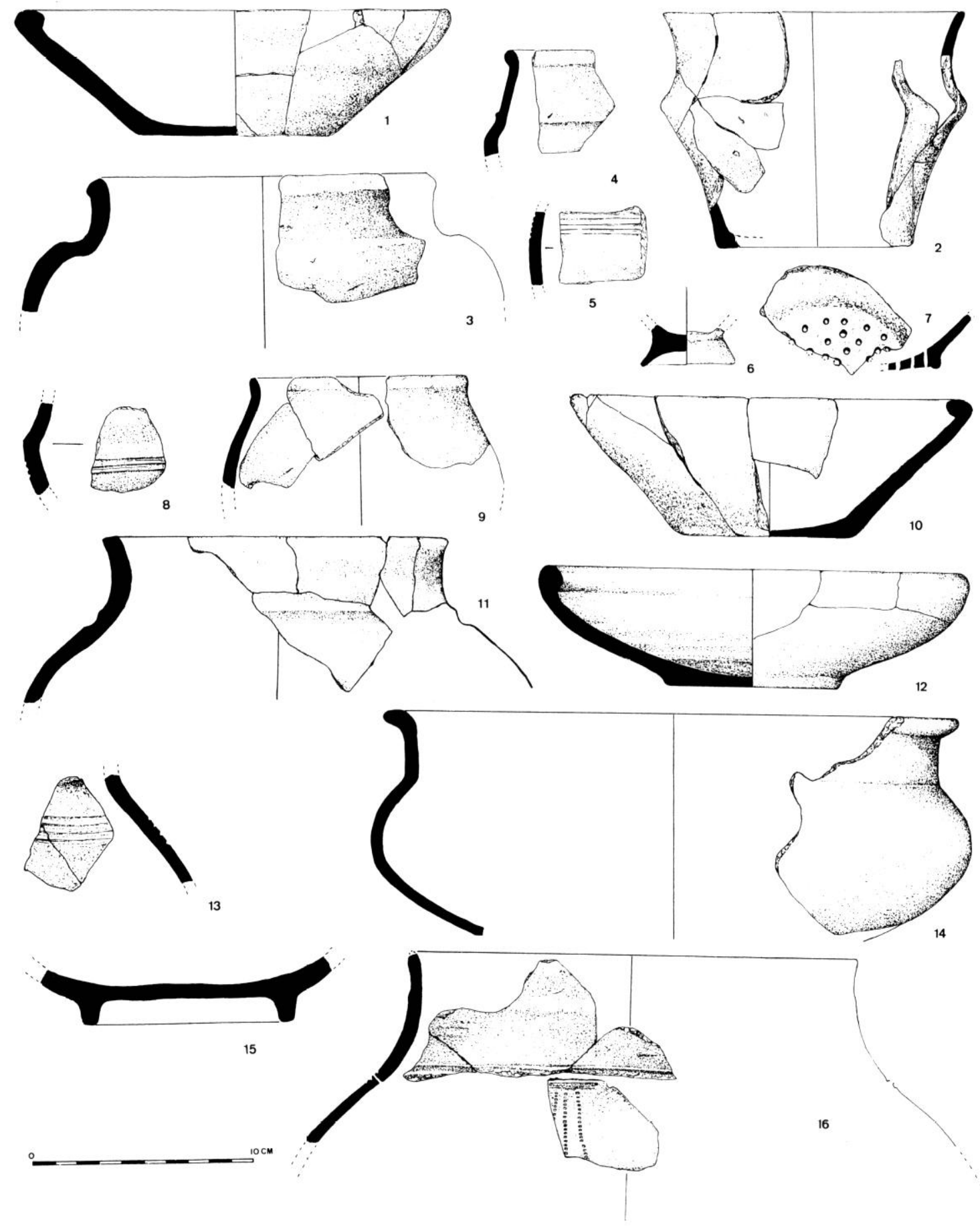

Fig. 19 - La Palut, céramique de l'Áge du Fer. 

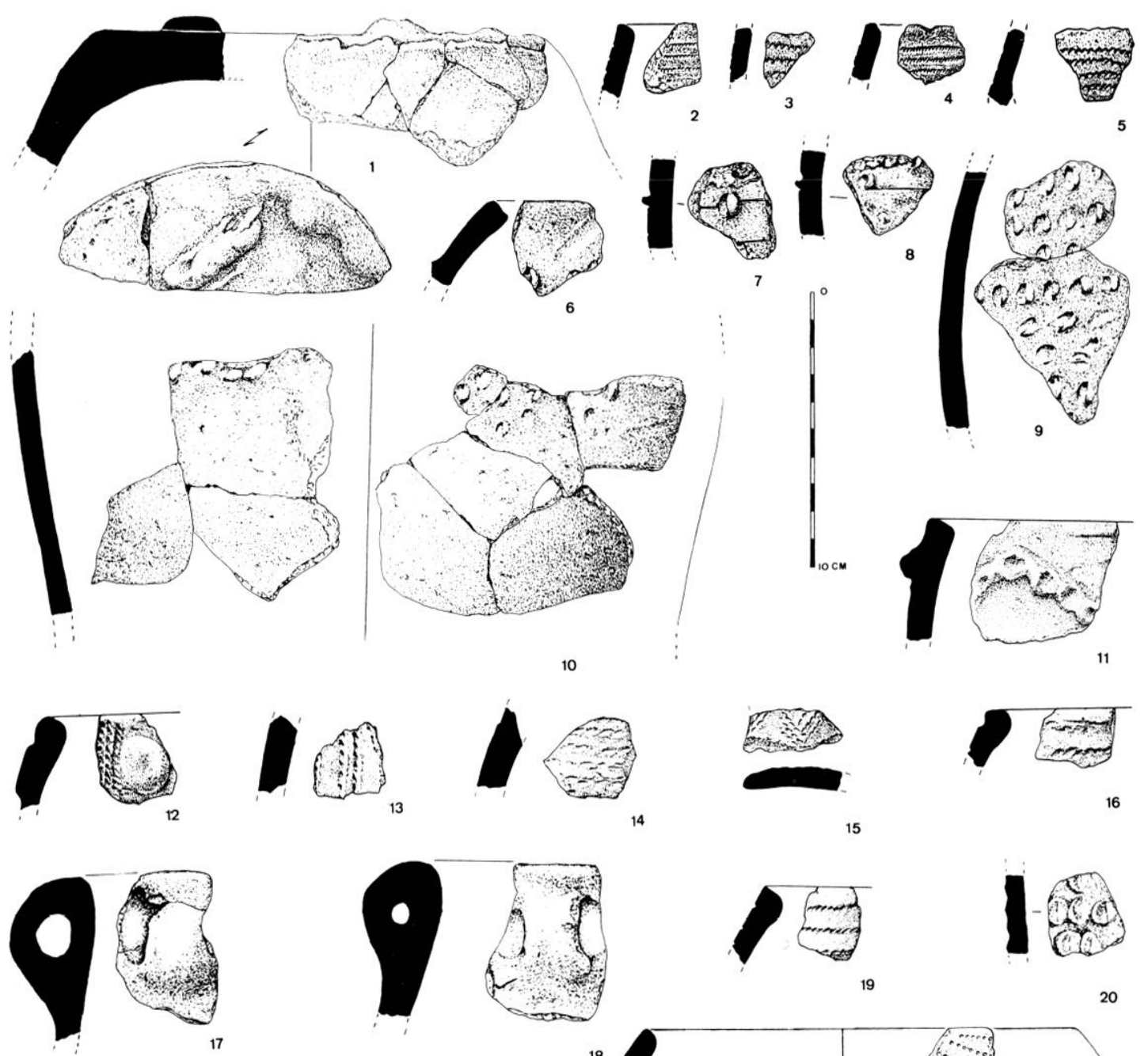

20
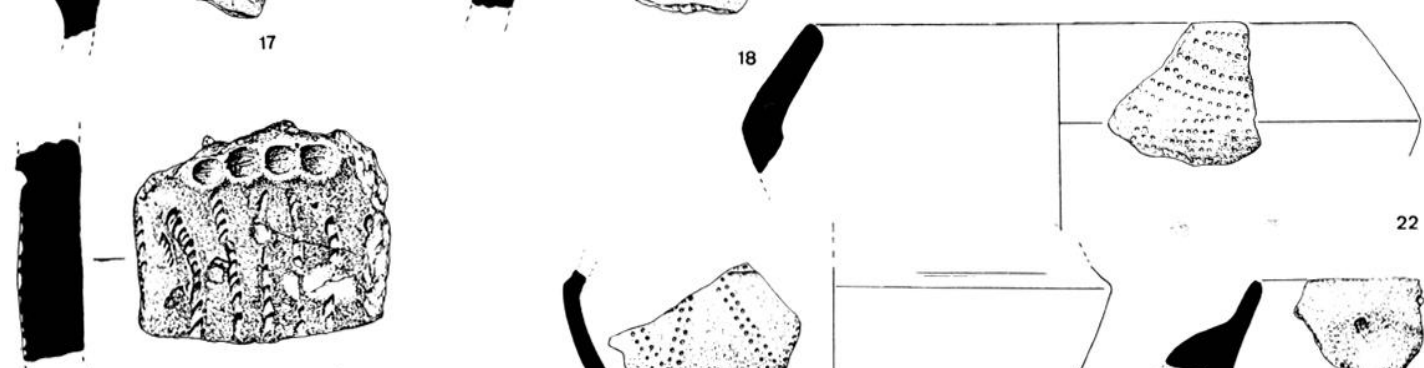

21
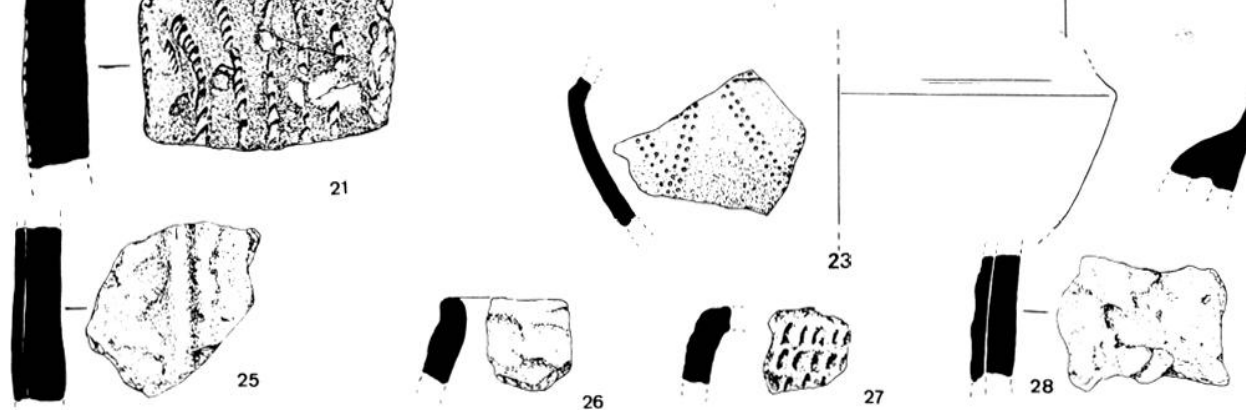

22

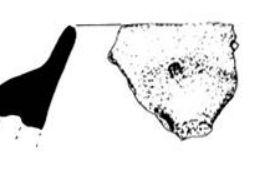

24

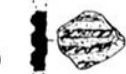

Fig. 20 - Sites divers de Charente et Charente-Maritime ayant livré de la céramique du Bronze ancien : 1-10, Les Orgeries à Courcoury (Charente-Maritime); 11-20, Le Vieux Bourg à Merpins (Charente); 21, Font-Rase à Barbezieux-Saint-Hilaire (Charente); 22, Chez les Brungs à Biron (Charente-Maritime); 23-29, Les Guédards à Montils (Charente-Maritime). 

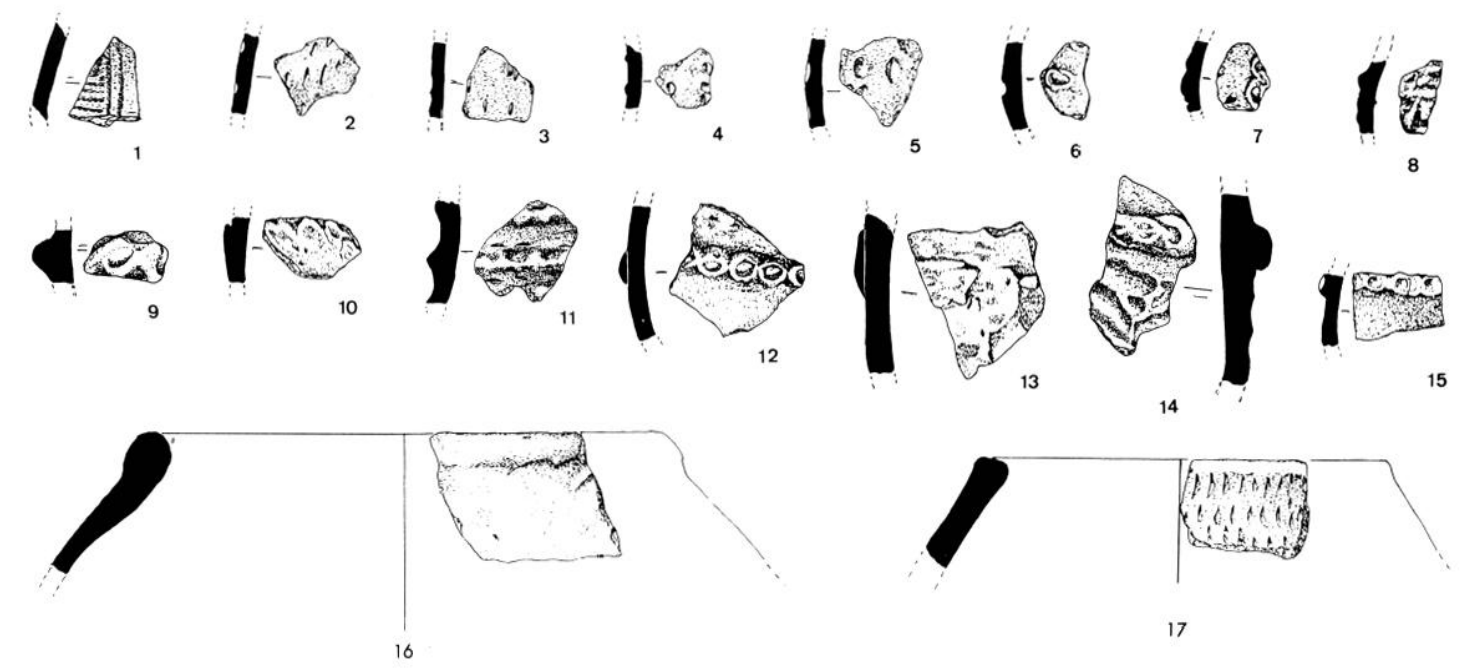

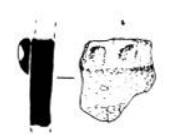

18

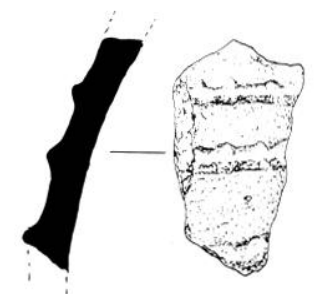

24

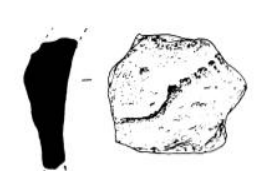

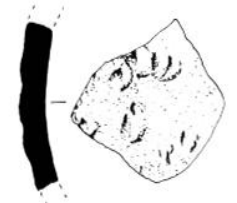

19

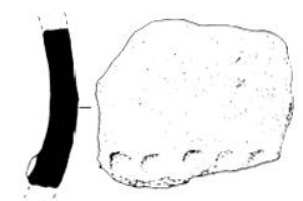

25

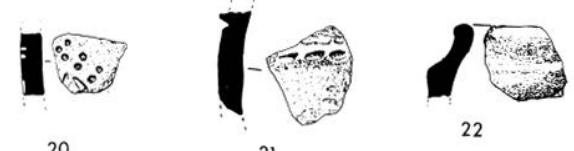

21

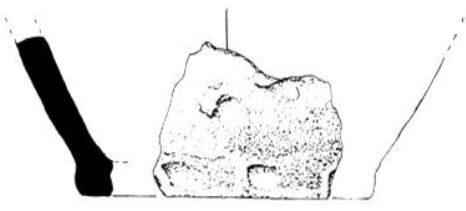

26

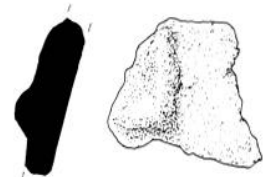

31
28

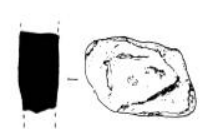

29

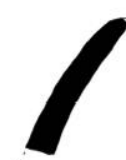

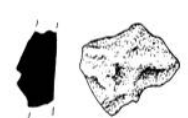

30

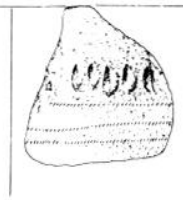

33

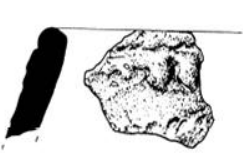

27

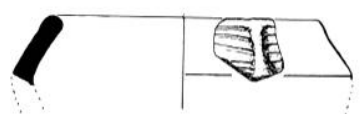

32

Fig. 21 - Sites divers de Charente et Charente-Maritime ayant livré de la céramique du Bronze ancien : 1-15, L'Entrée à Colombiers (Charente-Maritime); 16-19, La Cornelle à Montils (Charente-Maritime); 20-22, 33, Chez Coindreau à Colombiers (CharenteMaritime); 23, Cordis à Marignac (Charente-Maritime); 24-26, Jarlac à Montils (Charente-Maritime); 27-32, Le Vieux Bourg à Merpins (Charente). 
Le Vieux Bourg à Merpins (Charente)

Cet éperon barré, à la confluence de la Seugne et du Né, est l'un des plus grands de la Saintonge. C'est J. Gomez qui le premier a signalé des tessons découverts lors des travaux de restauration des vestiges médiévaux (Gomez, 1980). Il s'agit de décors à la cordelette, verticaux (fig. $20, \mathrm{n}^{\text {os }} 12,13$ ), horizontaux $\left(\mathrm{n}^{\text {os }} 14,16,19\right)$ et en chevrons sur une anse $\left(\mathrm{n}^{\circ} 15\right)$. A signaler l'association de lignes verticales à la ficelle et d'un bouton déprimé placé immédiatement sous un bord rentrant, comme à La Palut $\left(n^{\circ} 12\right)$. Il existe aussi des cordons digités, parfois en arceau sous un bord ( $\left.n^{0} 11\right)$, des coups d'ongle $\left(n^{0} 20\right)$ et des anses placées directement sur le bord ( $\mathrm{n}^{\text {os }} 17$, 18). Tout ce matériel montre d'évidentes parentés avec la céramique de La Palut.

\section{La Font-Rase à Barbezieux-Saint-Hilaire (Charente)}

Des ramassages de surface nous ont fourni, sur ce site proche d'un petit affluent du Né, un tesson épais bien cuit dont le décor associe digitations en ligne et impressions verticales à la cordelette (fig. 20 , $n^{\circ} 21$ ). C'est avec beaucoup de réserves que nous mentionnons ce tesson, faute d'élément associé pour le moment.

\section{Le 'Terrier de Font-Belle à Segonzac (Charente)}

Avec les mêmes réserves, nous devons mentionner un tesson portant des impressions digitées, de qualité identique au précédent. Sur ces deux gisements, les photographies aériennes de J. Dassié révèlent des enclos circulaires, précisément dans la zone où a été recueilli ce tesson.

\section{Chez les Brungs à Biron (Charente-Maritime)}

Un calibrage du petit ruisseau le Médoc, affluent de la Seugne, a mis au jour des traces d'occupation commençant avec l'Artenacien. Nous y avons recueilli un tesson de vase biconique décoré de lignes pointillées obliques (fig. $20, \mathrm{n}^{0} 22$ ).

\section{Les Guédards à Montils (Charente-Maritime)}

Les déblais d'un calibrage de la Seugne dispersés sur les champs environnants nous ont donné des éléments intéressants : un tesson à décor de grands zigzags pointillés (fig. $20, \mathrm{n}^{0} 23$ ) rappelant de très près, par sa pâte, son profil et son décor, un des vases de La Palut (fig. $6, \mathrm{n}^{\circ} 1$ ). Il s'y ajoute des décors plastiques, pastillages et cordons (fig. 20, $\mathrm{n}^{\text {os }} 25,26$, 28 ) ; un tesson à impressions profondes juxtaposées $\left(n^{\circ} 27\right)$ présente une angulation qui évoque certains vases à collerette interne et bord plongeant de La Palut.

\section{Le Petit Marais des Vaches à La Cornelle $\grave{A}$ Montils (Charente-Maritime)}

Sur une terrasse coupée par un bras artificiel de la Seugne, le Fossé des Terres, nous avons recueilli des bords de vases biconiques, l'un décoré de coups d'ongle en lignes horizontales (fig. 21, $\mathrm{n}^{\circ} 17$ ), l'autre de cannelures prenant appui sur un cordon vertical (fig. 2l, $\mathrm{n}^{0} 32$ ), des bords rentrants $\left(\mathrm{n}^{\circ} 16\right)$, des cordons digités ( $\left.n^{\circ} 18\right)$, des tessons ongulés $\left(n^{\circ} 19\right)$ et un petit tesson portant des lignes à la cordelette (non figuré).

\section{L'Entrée à Colombiers (Charente-Maritime)}

Au lieu-dit L'Entrée, le long d'un petit fossé alimenté par une source et rejoignant la rive gauche de la Seugne, nous avons recueilli un tesson à décor orthogonal à la cordelette (fig. $21, n^{0} 1$ ), des tessons à coups d'ongle ( $\left.\mathrm{n}^{\text {os }} 2-6\right)$, des cordons digités $\left(\mathrm{n}^{\text {os }} 7,9\right.$, $12,15)$, des pastillages et des décors plastiques divers $\left(n^{\text {os }} 8,11,13,14\right)$.

\section{Chez Coindreau à Colombiers (Charente-Maritime)}

Ce site se trouve près de la source de FondLoraud dans laquelle de l'industrie lithique, des tessons et des pilotis avaient été signalés au siècle dernier par G. Musset (1885); il s'agit probablement du même gisement. Certains des éléments rencontrés ne sont pas typologiquement indiscutables: un tesson à gros points imprimés (fig. 21, $\mathrm{n}^{0} 20$ ), un autre à cordon encadré de coups de poinçon obliques $\left(n^{\circ} 21\right)$ et un bord de vase à épaulement haut ( $\left.n^{\circ} 22\right)$. Toutefois la découverte récente par J.-M. Bouchet d'un tesson associant décor pointillé et coups d'ongle permet d'inscrire avec certitude ce site dans la liste des gisements du Bronze ancien (fig. 21, $\mathrm{n}^{\circ} 33$ ).

\section{Cordis à Marignac (Charente-Maritime)}

Sur cet éperon barré (parfois nommé "Cordie») 


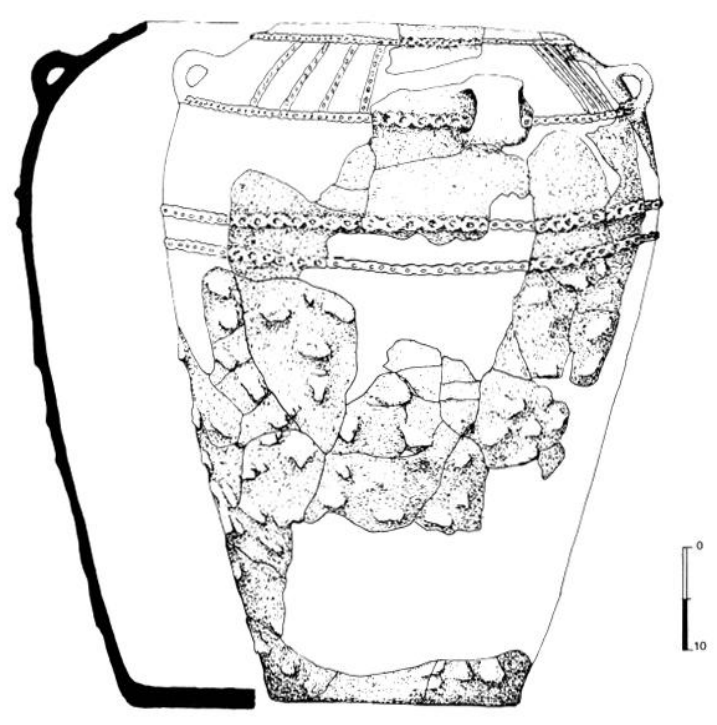

Fig. 22 - Les Grands Prés à Saint-Seurin-de-Palenne (Charente-Maritime) : grand vase à provisions.

dominant le Trèfle, affluent de la rive droite de la Seugne, l'un de nous avait récolté autrefois un tesson cordé (fig. 21, no 23) alors attribué au Campaniforme (Burnez, 1976). Il paraît aujourd'hui plus vraisemblable de ie rattacher au Bronze ancien, d'autant que ce site a livré d'autres vestiges de cette époque.

\section{Le Grand Marais de Jarlac À Montils (Charente-Maritime)}

Sur les bords de la Seugne, ce gisement ne semble pas avoir été occupé au Néolithique. Une importante occupation gallo-romaine recouvre des vestiges assez abondants du Premier Âge du Fer. De plus, nous avons recueilli un tesson à cordons pincés (fig. 21, no 24), un autre à cordon digité ( $\left.n^{\circ} 25\right)$ et un fond plat décoré de coups de spatule $\left(\mathrm{n}^{\circ} 26\right)$.

\section{Les Grands Prés ḋ Saint-Seurin-de-Palenne (Charente-Maritime)}

Ce gisement des bords de la Seugne qui a livré en surface un vase-support (Bouchet, Burnez, 1989) a aussi donné deux tessons décorés à la cordelette et un grand vase à provisions à col rentrant portant des cordons digités reliant quatre anses (fig. 22).

\section{**}

Il est assez frappant de constater que sur un territoire restreint (environ $40 \mathrm{~km}^{2}$ ) nos prospections dans les milieux humides font apparaître une densité tout à fait insoupçonnée de vestiges du Bronze ancien. On remarquera l'existence, aux environs, de deux grands éperons barrés connus depuis longtemps, Cordis et Merpins, dont quelques vestiges évoquent aussi cette période. Les marais et sites humides semblent avoir été à cette époque des lieux d'occupation privilégiés; il faut dire aussi que les conditions de préservation de la céramique y sont en général bien meilleures que sur les sites de hauteur. Dans une publication récente, nous avons souligné une notion à notre avis très importante : la complémentarité des milieux humides et des habitats situés sur la terre ferme (Roussot-Larroque et al., 1987).

D'autre part, en superposant la carte de répartition des vestiges céramiques que nous avons repérés (fig. 1, en haut) et celle des trouvailles métalliques du Bronze ancien et du début du Bronze moyen du même secteur, établie d'après le travail de J. Gomez (1980) pour l'ensemble du bassin de la Charente et complétée par des travaux postérieurs (fig. 1, en bas), il apparaît un groupement significatif correspondant plus particulièrement au bassin de la Seugne et de ses affluents, le Médoc et le Trèfle.

Ainsi, dans la zone sur laquelle ont porté nos prospections, on soulignera particulièrement la (ou les) hache(s) plate(s) du marais de Gâtebourse à Courcoury, dans un bras de la Seugne, non loin du site des Orgeries, la hache "plate simple à bords droits" de La Carcaudrie à Villars-en-Pons (Clouet, 1932), la hache à légers rebords de Réaux près du Trèfle (Gomez, 1980, fig. $9, \mathrm{n}^{\circ} 7$ ) et celle de Gémozac dans le bassin de la Seudre, mais non loin de notre secteur (Gachina, 1975); on rappellera aussi les haches à légers rebords de Merpins (Chaînet, 1915) et de Cordis (muséum de La Rochelle). On n'aura garde d'oublier une ou plusieurs épingles du Bronze ancien de Cordis : l'une d'elles, au musée de Royan, a été publiée par J. Gomez : c'est une épingle à tête plate triangulaire à enroulement sommital du type dit «en rame", caractéristique du Bronze ancien rhodanien. Du même site, R. Riquet avait signalé une épingle en béquille (Riquet, 1959); peut-être s'agit-il du même objet.

Dans ce secteur, l'occupation humaine se poursuit au Bronze moyen avec la petite hache à bords droits peu élevés du Fief à Clion associée à de la céramique à pastillages (Gaillard, Gomez, 1975), ou la hache à rebords médocaine et la hache à talon de "Chez Biron près de Pons" (Coffyn et al., 1973) lieudit inconnu, probablement commune de Biron, à $5 \mathrm{~km}$ de Pons, où nous avons précisément découvert le site de "Chez Les Brungs». On pourrait encore y ajouter la pointe de lance à flamme lancéolée de Marignac à proximité de Cordis (ibid.). Nous ne 
savons s'il faut retenir ici la hache à talon de type breton attribuée à un "dragage de la Charente" à Pons (?), provenance fort douteuse, la Charente n'arrosant pas cette commune (Gomez, 1980, p. 100). Dans ce contexte des trouvailles métalliques du bassin de la Seugne, il faudrait peut-être rappeler les deux petits récipients épais et ovales en terre cuite de La Palut qui ressemblent à des creusets, bien qu'ils ne portent pas de traces de cette sorte d'utilisation.

Grâce aux prospections aériennes de J. Dassié, avec qui nous avons entrepris une campagne de vérifications systématiques au sol, d'innombrables structures superposées, dont de nombreux cercles, ont été découvertes dans toute cette zone. Un de ces cercles entoure un tumulus en grande partie arasé. A ce propos, nous serions tentés de rappeler que, dans ce même bassin de la Seugne à Consac et à SaintMaurice-de-Tavernole (Charente-Maritime), des fouilles d'enclos circulaires effectuées par l'Association Archéologique et Historique de Jonzac sous la direction de J.Gaillard ont livré, en contexte funéraire, de la céramique à décors plastiques, cordons et pastillages, attribuée à une phase peutêtre tardive du Bronze moyen (Gaillard, 1980). Cette tradition des enclos circulaires, qui connaîtront au Bronze moyen et final le développement que l'on sait, pourrait bien remonter au Bronze ancien dans la région (Roussot-Larroque, 1987).

\section{COMPARAISONS ET DATATION}

\section{Les vestiges du NÉolithique final}

Pour le mobilier artenacien très classique de La Palut il est inutile d'énumérer les nombreux points de comparaison existants. Son principal intérêt est de fournir un site supplémentaire sur une carte de répartition qui s'enrichit régulièrement. L'attirance des Artenaciens pour les milieux humides se confirme au fur ct à mesure de nos prospections (RoussotLarroque et al., 1987). Une part sans doute importante de l'industrie lithique doit leur ètre attribuée, en particulier peut-être les microlithes; il est difficile d'être aussi affirmatif pour les flèches à pédoncule et ailerons équarris, type classiquement rattaché au Campaniforme mais connu aussi en milieu artenacien pur. Quant aux poignards en silex du GrandPressigny et "scies" à coches, types bien représentés dans l'Artenacien, quelques-uns apparaissent sporadiquement en milieu campaniforme. On ne peut donc ici se prononcer avec certitude, sachant surtout que ces types ont pu se prolonger quelque peu dans le Bronze ancien régional.

\section{LES VESTIGES CAMPANIFORMES}

La Palut est le cinquième des sites repérés récemment par J.-M. Bouchet dans le bassin inférieur de la Seugne. Au fur et à mesure des prospections, la répartition préférentielle en bord de mer des "habitats» (ou du moins des traces d'occupation) dans la région tend à s'estomper. Typologiquement la céramique appartient à l'ensemble classique de la zone atlantique. La pendeloque en griffe en test de bivalve est étroitement comparable à celles des mégalithes du Terrier de Cabut à Anglade ou de La Mothe à Espiet (Gironde), probablement associées aussi au Campaniforme. L'anneau tronconique en os est connu, dans le Centre-Ouest, au dolmen de La Planche-à-Puare dans l'île d'Yeu (Vendée) et au dolmen E136 de Taizé (Deux-Sèvres); R. Joussaume les attribue au Campaniforme, mais les exemplaires trouvés en milieux clos en France, essentiellement dans l'axe Saône-Rhône, appartiennent au début du Bronze ancien (Bill, 1973) comme ceux d'Italie du Nord connus en contextes poladiens.

\section{LEs vestiges DU BRonZE ANCIEN}

\section{Principales caractéristiques}

Par son exceptionnelle richesse en mobilier céramique, le site de La Palut fait surgir de l'ombre un nouveau complexe culturel du Bronze ancien dont on ne connaissait jusqu'ici que des éléments dispersés. Si l'industrie lithique ne semble guère évoluer par rapport au Néolithique final, avec la persistance probable de flèches à pédoncule et ailerons, de racloirs latéraux (ou couteaux) ou de "scies" à coches, la poterie s'individualise en revanche très clairement par rapport à l'Artenacien et au Campaniforme. Formes et décors manifestent une originalité marquée. Parmi les formes caractéristiques, on retiendra les vases biconiques à bord souvent rétréci, les carènes parfois très hautes, les anses placées directement sur le bord, les cruches et les poteries à collerette interne. Moins spécifiques, les récipients tronconiques bas constituent cependant ici une catégorie particulièrement abondante et bien typée, assez homogène aussi par ses dimensions. Parmi les décors typiques de ce complexe culturel du Bronze ancien figure en premier lieu le décor à la cordelette ou pseudo-cordé, en lignes horizontales, verticales, orthogonales, chevrons, vagues, etc. $\mathrm{Au}$ - 
tres décors caractéristiques, les motifs géométriques incisés, pointillés ou combinant incision et pointillé, et les décors plastiques, coups d'ongle, cordons simples ou digités, pastillages. Quelle que soit la technique utilisée pour ces vases décorés du Bronze ancien, l'ornementation y est en général plus envahissante qu'au Néolithique final. Cette tendance est particulièrement sensible pour la céramique d'usage où même les grandes jarres portent des cordons disposés parfois en motifs complexes. Enfin, décoratives ou utilitaires, les prises en arceau constituent également un élément repère.

\section{Domaine géographique}

Ces dernières années, comme nous l'avons vu, les prospections en Saintonge méridionale et particulièrement dans le bassin de la Seugne ont révélé une notable densité de sites appartenant au mème groupe culturel que celui de La Palut. En outre, dans le bassin de la Charente, des vestiges isolés ou de petits ensembles présentant des caractères voisins ont été récemment signalés (Gomez, 1982): motifs cordés du Fort des Anglais à Mouthiers-sur-Boëme, alias Vœuil-et-Giget (Charente) (Gomez, l.c.) et de La Sauzaie à Soubise (Charente-Maritime) (Pautreau et al., 1974), vases biconiques de Merpins (Charente) et de Cordis à Marignac (Charente-Maritime), vases à épaulement haut, resserrés à l'ouverture, de Piedemont à Port-des-Barques (Charente-Maritime) (Gomez, l.c.), arceaux en relicf du même Piedemont, de La Vallée et d'un site inédit de Saujon (CharenteMaritime) ou du Fort des Anglais et peut-être de la grotte du Quéroy à Chazelles (Charente). On pourrait probablement leur adjoindre les décors plastiques, cordons digités, coups d'ongle et pastillages de plusieurs de ces mêmes sites, dont la spécificité chronologique est moins assurée. Récemment, J. Gomez a publié un vase ovale de la grotte des Perrats à Agris (Charente), très proche par sa forme et son décor de celui de La Palut (fig. 5, no 26). Il provient d'un niveau du Bronze ancien qui a livré aussi d'autres poteries décorées comparables à La Palut, hormis cependant le décor à la cordelette (Gomez, 1989).

Au-delà de ces sites charentais, plusieurs traits distinctifs du style céramique de La Palut se reconnaissent sur une aire géographique beaucoup plus large (fig. 23). On en retrouve la trace vers le Nord et le Nord-Ouest. En Poitou, on peut citer le tumulus de Laverré (Patte, 1971) et le Camp Allaric à Aslonnes (Vienne) avec des décors cordés parfois orthogonaux et des profils biconiques (Pautreau, 1979), La Viaube à Jaunay-Clan (Vienne) avec des décors pseudo-cordés et des formes biconiques (Taillet, 1953) ou encore le tumulus de Fleuré (Vienne) avec une poterie biconique à motifs orthogonaux incisés et pointillés et de la céramique à décor plastique (Patte, l.c.). En Vendée, on retiendra les sites de Champ-Durand à Nieul-sur-l'Autise et La Boilivière à L'Aiguillon-la-Chaize avec des tessons à prise arciforme (Joussaume, 1981), un tesson à motifs orthogonaux cordés et des pastillages à La Tranchesur-Mer (Joussaume, Boiral, à paraître) ou encore des vases à décor de coups d'ongle et une tasse carénée à anse à Quineveau à Avrillé (Cadot, Joussaume, 1988). Plus au Nord, ce style s'étend à la LoireAtlantique, avec les tessons à décor cordé, parfois orthogonal, du Camp des Prises à Machecoul (Joussaume, l.c.) ou de Luzéronde à Noirmoutier-en-l'lle (Letterlé, 1987-1988). Au même ensemble, nous rapportons aussi un fragment de vase biconique à décor cordé (inédit, renseignement Tardivo) provenant de la Loire près d'Amboise (Indre-et-Loire).

Vers le Sud, des éléments caractéristiques du même complexe ont été reconnus et inventoriés par J. Roussot-Larroque: une vingtaine de sites ont livré des tessons à décor cordé ou pseudo-cordé, en lignes horizontales, verticales, orthogonales, en vagues, en chevrons, en arceaux... On pourrait $y$ ajouter un nombre bien supérieur de sites ayant fourni des vases biconiques, des décors incisés et pointillés ou des décors plastiques divers (RoussotLarroque, 1987). Seul jusqu'ici, en Aquitaine, le site de La Lède du Gurp à Grayan-et-l'Hôpital (Gironde) a livré l'arceau en relief. De l'inventaire de ce motif décoratif (Gomez, 1982) on doit en effet exclure le tesson du Martinet à Sauveterre-la-Lémance qui provient, en réalité, d'une anse "à moustaches» de la transition Néolithique ancien/Néolithique moyen (Roussot-Larroque, 1977). Ces éléments atteignent les Landes et les Pyrénées occidentales où l'on retrouve les décors cordés, les profils biconiques et les décors plastiques sur quelques sites de surface et surtout dans des grottes et des tumulus, jusque sur le Plateau de Ger (tumulus B du Taillan). De là, des influences se sont-elles exercées vers le centre et l'est du domaine pyrénéen? Certains indices le feraient penser, par exemple un tesson à décor de cordelette et d'impressions de La Petite Caougne de Niaux (Ariège).

Comme en Saintonge, certains sites aquitains occupent des milieux palustres (La Lède du Gurp), des buttes dominant des marais (Anglade) ou des sols sableux, mais sans exclusive; les sites de hauteur sont également réoccupés. Des éléments de mobilier comparables indiquent des sépultures en grottes (dans les Pyrénées occidentales) et sous tumulus (en 


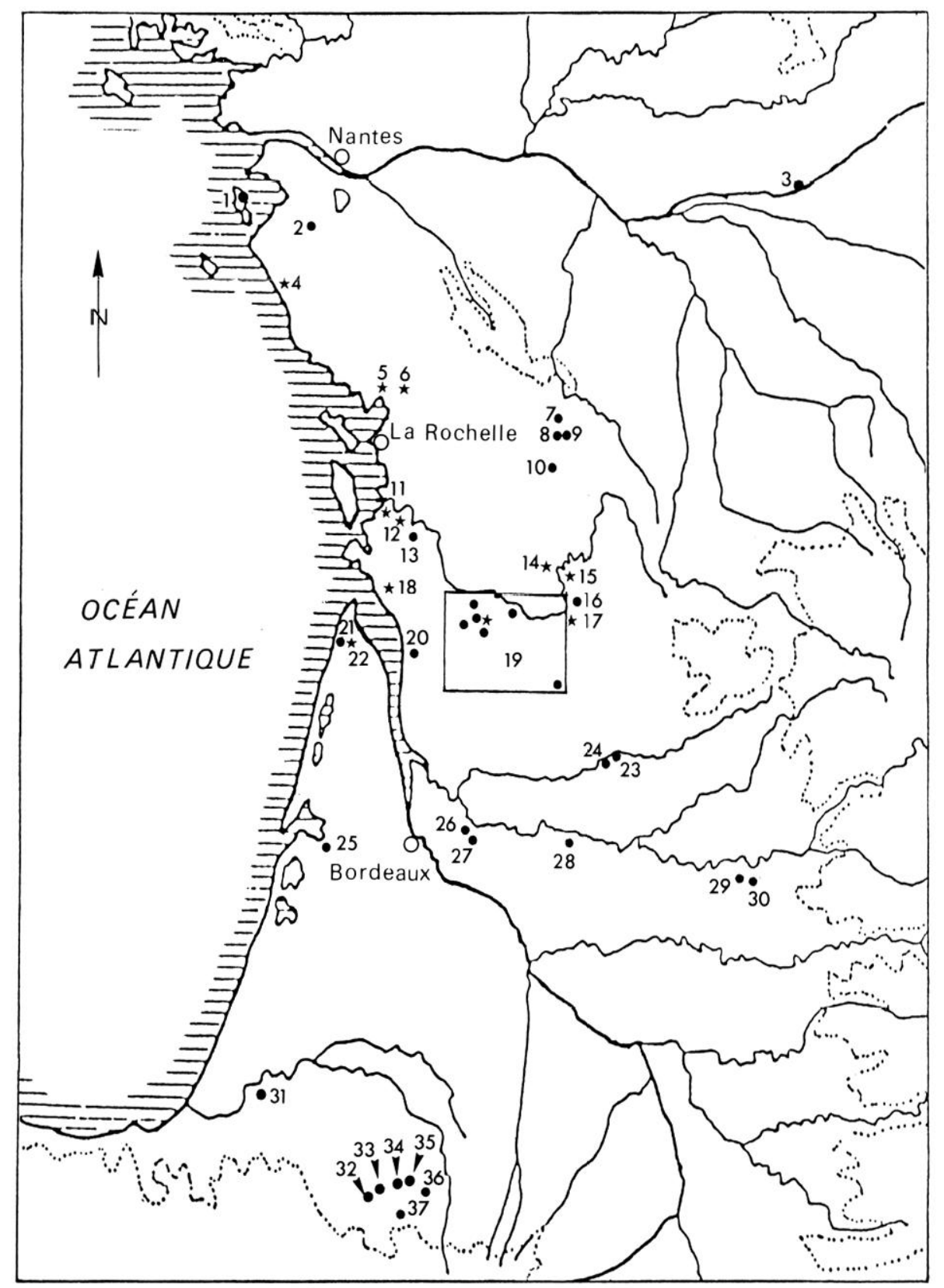

Fig. 23 - Sites ayant livré des éléments comparables au Bronze ancien de La Palut : •, décor cordé ou pseudo-cordé; ${ }^{*}$, cordon en arceau ; 1, Luzéronde à Noirmoutier-en-l'Ile (Vendée); 2, Camp des Prises à Machecoul (Loire-Atlantique); 3, la Loire près d'Amboise (Indre-et-Loire); 4, Pointe de Grosse-Terre à Saint-Hilaire-de-Riez (Vendée); 5, Boislivière à L'Aiguillon-la-Chaize (Vendéc); 6, Champ-Durand à Nicul-sur-l'Nutise (Vendéc); 7, La Viaube à Jaunay-Clan (Vienne); 8, Camp Allaric à $\Lambda$ slonncs (Vienne); 9, tumulus de Laverré à Aslonnes (Vienne); 10, tumulus de Russell à Saint-Saviol (Vienne); 11, Piedemont à Port-desBarques (Charente-Maritime); 12, dolmen de La Pierre-Levée à La Vallée (Charente-Maritime); 13, La Sauzaie à Soubise (CharenteMaritime); 14, grotte des Perrats à Agris (Charente); 15, grotte du Quéroy à Chazelles (Charente); 16, Le Fort des Anglais à Mouthiers-sur-Boëme (Charente); 17, Le Bois de Mativo à Magnac-sur-Touvre (Charente); 18, site inédit de Saujon (CharenteMaritime); 19, sites du bassin de la Seugne (cf. fig. 1, en haut); 20, Le Terrier-Ricard à Anglade (Gironde); 21, La Négade à Soulacsur-Mer (Gironde); 22, La Lède du Gurp à Grayan-et-l'Hôpital (Gironde); 23, La Fontaine de la Demoiselle à Saint-Léon-sur-l'Isle (Dordogne); 24, grotte de Leygonie à Neuvic (Dordogne); 25, Le Truc du Bourdiou à Mios (Gironde); 26, Roquefort à Lugasson (Gironde) ; 27, ruisseau souterrain des Clusets à Blasimon (Gironde); 28, ruisseau souterrain de La Fontanguillère à Rouffignac-deSigoulès (Dordogne); 29, grotte de La Bergerie à Caniac-du-Causse (Lot); 30, couche A2 de la doline de Roucadour à Thémines (Lot); 31, site inédit de Candresse (Landes); 32, tumulus 2 d'Artix (Pyrénées-Atlantiques); 33, tumulus de Cobet à Artix (PyrénéesAtlantiques); 34, grotte de Prédigadère à Serres-Castet (Pyrénées-Atlantiques); 35, tumulus 2 de Serres-Castet (PyrénéesAtlantiques); 36, tumulus B de Taillan à Ger (Pyrénées-Atlantiques); 37, grotte de Poeymaü à Arudy (Pyrénées-Atlantiques). 
Poitou comme en Aquitaine); comme nous l'avons suggéré plus haut, des enclos circulaires pourraient être liés à ce groupe culturel (cf. aussi RoussotLarroque, 1987).

Au-delà de cette province stylistique, correspondant en gros à une Aquitaine élargie de la Loire aux Pyrénées, s'étend vers l'Est et le Nord-Est une vaste zone où la céramique du Bronze ancien est encore peu connue. Peut-être peut-on évoquer ici des tessons à décor cordé ou pseudo-cordé du Quercy (couche A2 de la doline de Roucadour à Thémines et grotte de La Bergerie à Caniac-du-Causse, dans le Lot), bien que les formes plus globuleuses puissent appartenir à une phase un peu plus récente de développement. En Auvergne à Sanssac-l'Église (Haute-Loire), un tesson à lignes cordées orthogonales accompagné de vases à cordons lisses ou digités paraît assez proche de ceux du Bronze ancien de La Palut (Daugas et al., 1972). Il en est de même, dans l'Est de la France, de plusieurs autres vestiges isolés ou petits ensembles de céramique, avec des vases à décors cordés complexes rapportés parfois, sans grande vraisemblance, au Campaniforme.

\section{Datations}

Les conditions de dépôt n'ont pas encore permis de dater le niveau du Bronze ancien de La Palut. On dispose heureusement de quelques datations ${ }^{14} \mathrm{C}$ pour le bassin de la Charente : Le Fort des Anglais, $38.30 \pm 100 \mathrm{BP}$ (Gif 5733); Piedemont, $3510 \pm 100 \mathrm{BP}$ (Gif 4680) (Gomez, 1982); Les Perrats à Agris, $3540 \pm 60 \mathrm{BP}(\mathrm{Gif} 7609) ; 3450 \pm 90 \mathrm{BP}$ (Gif 7259), $3280 \pm 60$ BP (Gif 7260) (Gomez, 1989). Elles sont à comparer aux dates proposées pour des vases biconiques élancés du Nord-Ouest de la France, pourvus parfois de prises en arceau ou de décors cordés : Lingreville (Manche) $3660 \pm 110 \mathrm{BP}$ (Gif 3917) (Verron, 1977) ou Saint-Just (Ille-etVilaine) $3940 \pm 80$ BP (Gif 5235) (Le Roux et al., 1981). Cependant, pour les tessons cordés du Fort des Anglais, des résultats plus récents ne sembleraient pas confirmer la date haute proposée d'abord (Diot el al., 1987 ; Gomez, 1989).

Dans les Pyrénées-Atlantiques, d'autres datations pour des sépultures à mobilier comparable indiquent également le Bronze ancien et le début du Bronze moyen : grotte de Poeymaü à Arudy (niveau ayant livré le tesson cordé) $3970 \pm 270 \mathrm{BP}$ (Ly 1383); tumulus 6 de Lescar, $3840 \pm 80$ BP (Gif 2515); sépulture en grotte de Chocojapo, Cézy à Laruns, $3720 \pm 100$ BP (Ly 3246); tumulus BBL II de Boueilh-Boueilho-Lasque, $3720 \pm 120 \mathrm{BP}$ (Gif 5525); grotte de Prédigadère à Serres-Castet, $3230 \pm 100$ BP (Ly 3480).
C'est donc bien au Bronze ancien que la majorité des dates ${ }^{14} \mathrm{C}$ situe ces ensembles, comparables sur bien des points à celui de La Palut. Quelques dates pourtant font le lien avec le Bronze moyen, autour de 3200 BP (Agris, Serres-Castet). Ces dates confirment la persistance avérée, du Bronze ancien à une phase parfois avancée du Bronze moyen, de certains décors (cordés, incisés-pointillés, plastiques) ou de quelques formes (vases biconiques). Ainsi, des vases biconiques à décors orthogonaux incisés et pointillés, des cruches, des pots à décor plastique, cordons simples ou pincés, parfois orthogonaux, pastillages, coups d'ongle, ont été recueillis dans des niveaux du Bronze moyen de La Lède du Gurp, datés par la présence d'un moule de hache à bords droits de type médocain (Frugier et al., 1983). De même, des jarres à cordons et pastillages contenaient les dépôts du Bronze moyen des Vigneaux à Talais et de Mayan à Vendays-Montalivet (Gironde).

Reste à déterminer le moment d'apparition de ces décors. Des indices suggèrent une phase déjà avancée du Bronze ancien, à l'instar de ce que l'on sait pour le Jura français et la Suisse occidentale. La tasse décorée à la cordelette de la station littorale de Morges-les-Roseaux (Vaud) sur le lac Léman (Bill, 1981) ou, mieux encore, de bonnes associations en stratigraphie au Garage Martin à Yverdon (Vaud) sur le lac de Neuchâtel (Kaenel, 1976) ou à Clairvaux-les-Lacs (A.-M. et P. Pétrequin, 1978), toujours en milieux humides, indiquent une phase finale du Bronze ancien, faisant transition avec le Bronze moyen et contemporaine des haches à légers rebords. Par la suite, dans les Pays d'Ouest, il semblerait que l'on assiste à une évolution sans rupture des formes céramiques, au moins dans une première partie du Bronze moyen. Une certaine continuité semble donc marquer le passage du Bronze ancien au Bronze moyen dans le domaine de la céramique. Par certains traits, cette unité de développement peut s'observer aussi dans les productions métalliques (transition de la hache à légers rebords à la hache à bords droits, toujours dominante dans le Bronze moyen d'Aquitaine). Pour le moment, les associations entre mobilier métallique et céramique sont si rares qu'on ne peut encore risquer de conclusions péremptoires. Ici, en tout cas, se pose donc le problème de la validité d'une coupure franche entre Bronze ancien et Bronze moyen que beaucoup de caractères tendent à unir plutôt qu'à séparer.

\section{Origines et affinites du Bronze ancien de La Palut}

De l'ensemble des données que nous venons d'exposer commencent à se dégager les grands traits 
d'un complexe culturel occidental du Bronze ancien, pour lequel un essai de synthèse récent propose le nom de "Pseudo-Cordé atlantique» (Guilaine et al., 1988). L'emploi de ce terme d'attente ne doit pas suggérer un clivage préconçu entre domaine atlantique et domaine continental. Dans un précédent travail, J. Roussot-Larroque a rassemblé un faisceau d'indices suggérant, au contraire, des connexions entre les régions de l'Ouest et le domaine continental (Roussot-Larroque, 1987).

$\mathrm{Au}$ niveau le plus général, des comparaisons sont en effet possibles avec divers groupes culturels du Bronze ancien d'Europe centrale et balkanique où apparaît vers la même époque la céramique à décors cordés, incisés-pointillés et plastiques. Ces groupes - dont certains sont peut-être issus du Cordé - ont exercé des influences sensibles jusqu'en Suisse occidentale (Yverdon, Morges-les-Roseaux) et en France orientale (Clairvaux). Ces mêmes influences, relayées probablement par le bassin inférieur du Rhin, se font sentir aussi dans le groupe des urnes biconiques à prises arciformes et/ou décors cordés de la Hollande, de la Belgique, et du NordOuest de la France, de la Picardie à la Normandie et à la Bretagne. De là, il ne serait pas invraisemblable que le Centre-Ouest et l'Aquitaine aient à leur tour été atteints.

A d'autres égards, cependant, la céramique du Bronze ancien de La Palut frappe par l'originalité de certaines formes ou décors, dont on ne connaît pas jusqu'ici d'équivalents exacts plus à l'Est : vases à collerette interne ou bord plongeant, décors pointillés ou incisés en grecques ou en damiers, cruches décorées... L'échantillon dont nous disposons, beaucoup plus large que ce que l'on connaissait jusqu'ici, donne de la cohérence à des éléments jusque là dispersés, suggérant l'existence d'un véritable complexe culturel régional.

Comment ce complexe culturel s'insère-t-il dans les traditions locales du Néolithique final ou Chalcolithique? Si des liens de filiation directe avec l'Artenacien ne semblent guère probables, quelques aspects pourraient évoquer une possible ascendance campaniforme du Bronze ancien de La Palut, par exemple les bandes parallèles, pointillées ou incisées de quelques cruches (fig. $8, \mathrm{n}^{\circ} 1,3,8$ ), cette forme étant par ailleurs connue pour apparaître vers la fin de l'évolution du Campaniforme dans le domaine oriental. De semblables ascendances campaniformes ont été évoquées pour certains tessons de Bretagne provenant de sites de surface comme Saint-Nicolasdu-Pélem (Côtes-du-Nord) ou de terres de tumulus comme à Kersandy en Plouhinec (Finistère) et SaintJude en Bourbriac (Côtes-du-Nord). Certaines analo- gies se font jour entre ces poteries armoricaines et celles de La Palut: décors incisés ou au peigne, parfois sur des anses plates, ou encore décors plastiques et coups d'ongle... Ainsi par exemple, les "petites protubérances coniques ou irrégulières" couvrant certains tessons de Saint-.Jude en Bourbriac, que $J$. Briard rapproche des pastillages aquitains (Briard, 1984), se compareraient peut-être mieux au décor de certains vases de La Palut (fig. 7, $n^{\circ} 13$ et fig. $9, n^{\circ} 4$ ) ou à celui d'un tesson encore inédit de Diconche à Saintes. De même, on peut évoquer un tesson de La Palut (fig. 10, $\mathrm{n}^{\circ}$ 9) pour les impressions en chevrons emboités d'un fragment de cruche des alignements du Moulin à Saint-Just (Ille-et-Vilaine) (Briard, 1984, fig. 92, $\mathrm{n}^{\circ} 5$ ). Sur ce site ont été également trouvés une urne biconique à prise en arceau et des campaniformes. Une date de $3940 \pm 80$ BP (Gif 5235) (Le Roux et al., 1981) semblerait confirmer l'ancienneté relative de ces vestiges, dont cependant l'association n'est pas absolument établie. En Vendée, un cordon en arceau, peu accentué d'ailleurs, a été recueilli à La Pointe de Grosse-Terre à Saint-Hilaire-de-Riez en contact avec des tessons campaniformes (Longuet et al., 1985). J. Roussot-Larroque a signalé d'autres cas d'association de l'arceau en relief avec des campaniformes, de la Hongrie à l'Italie du Nord; il faut bien dire cependant que ce motif s'y rencontre également dans d'autres contextes du Bronze ancien d'où le Campaniforme est absent (Roussot-Larroque, 1987).

Mieux vaut, sans doute, éviter pour le moment de prendre une position définitive car la majeure partie de la céramique de La Palut est, en apparence, fort éloignée du Campaniforme dont, à vrai dire, on connaît encore mal la poterie domestique. Ici se pose le problème plus général de l'origine des décors plastiques dans divers groupes culturels du Bronze ancien. Pour certains, ces décors dériveraient des cordons, coups d'ongle et digitations ornant la céramique d'usage associée au Campaniforme dans certains ensembles - plutôt tardifs d'ordinaire connus des Iles britanniques à l'Italie du Nord. Jusqu'ici, dans les Pays d'Ouest, aucun élément vraiment décisif ne peut être avancé en faveur de cette hypothèse; les campaniformes de La Grande Pigouille à Belluire, site tout proche de La Palut, sont accompagnés d'une céramique domestique assez abondante mais pratiquement dépourvue de décors plastiques (Bouchet et al., à paraître). Si les cruches à bandes décorées et les décors plastiques de La Palut peuvent se réclamer d'une quelconque ascendance campaniforme, ce n'est donc sans doute pas dans le contexte régional qu'il faut en chercher l'origine. 
En tout cas, il convient désormais d'exclure de la liste des campaniformes une série de décors à la cordelette qu'on y avait insérés, et de les inclure dans le style de La Palut. De ce fait, les campaniformes "cordés" sont désormais moins nombreux dans le Centre-Ouest que ne le laissaient croire de précédents inventaires; du même coup, leur répartition s'en trouve quelque peu modifiée. Vu l'importance théorique accordée au Campaniforme All Over Corded, considéré en général comme le plus ancien de la série, beaucoup d'attention devra être portée à cette révision et à ses conséquences.

Il faut bien remarquer aussi l'absence, ici, des décors classiquement considérés comme "épicampaniformes", en particulier du décor barbelé bien connu dans le Midi et attesté aussi en Auvergne. La comparaison de la céramique de La Palut avec l'important ensemble provençal du Camp de Laure (Le Rove, Bouches-du-Rhône) nous a permis à cet égard de constater des différences marquées (nos remerciements vont à $\mathrm{J}$. Courtin qui nous a généreusement communiqué les dessins de ce mobilier encore inédit). Fort curieusement, en revanche, certains éléments caractéristiques du style de La Palut (anses placées sur le bord, décors pointillés-incisés, damiers et grecques pointillées) trouveraient des échos dans des ensembles, bien plus lointains pourtant, du Bronze ancien de l'Italie du Sud avec lequel des relations directes sont cependant bien peu probables.

En tout cas, le style céramique de La Palut frappe par sa forte originalité par rapport aux cultures régionales antérieures. Dans quelle mesure cela tient-il à des influences étrangères? Il n'est pas facile d'en décider dans l'état actuel des recherches. Quelques objets de parure comme l'anneau tronconique en os de La Palut, l'épingle en os à tête en palette perforée de Diconche ou l'épingle métallique à tête en rame de Cordis attestent des relations avec les groupes du Bronze ancien de France orientale, eux-mêmes liés au domaine centre-européen. Cela ne peut guère surprendre puisque des objets d'ascen- dance analogue ont été découverts dans les régions intermédiaires : Massif Central, Languedoc ou Quercy. Dans le mobilier métallique comme dans la céramique on a certainement exagéré autrefois les influences de la seule "Civilisation du Rhône" dans le Sud de la France; pourtant, jusque dans le CentreOuest et l'Aquitaine, on peut déceler des influences orientales venues sans doute d'un domaine plus large que celui de la seule culture rhodanienne et incluant probablement le Sud de l'Allemagne et l'Italie du Nord. Ainsi par exemple, à la fin du Bronze ancien, en Aquitaine surtout, on peut envisager à la suite de R. Riquet de telles influences "rhodaniennes" pour le poignard à triangles incisés de Cissac-Médoc (Gironde) ou pour certaines haches à rebords peu marqués, proches du type de Neyruz. Ces relations est-ouest s'affirment encore, au début du Bronze moyen, avec la hache du type d'Ollon du dépôt de Martillac (Gironde). A cette époque où la métallurgie du bronze commençait seulement à se généraliser, il est possible que les prototypes aient couvert des distances importantes. La céramique, plus fortement ancrée en général dans la tradition locale, a-t-elle suivi le mouvement? Les conditions particulières qui ont présidé à la mise au jour des vestiges archéologiques de La Palut ne permettent pas, pour l'heure, de résoudre de tels problèmes, mais la reprise des recherches dans des conditions favorables pourrait fournir, avec des niveaux en place, de nouveaux éléments de réponse.

Jean-Marc Bouchet ${ }^{1}$, Claude Burnez Julia Roussot-Larrogue, Alain Villes ${ }^{2}$

1. J.-M. Bouchet, La Jard, 17460 Thenac.

2. Cl. Burnez, J. Roussot-Larroque et A. Villes, Institut du Quaternaire, Centre François Bordes, Université de Bordeaux I, avenue des Facultés, 33405 Talence Cedex. 


\section{BIBLIOGRAPHIE}

Barthe J.-M., Marsan G., Valicourt E. de

1985 : La grotte de Prédigadère (commune de Castet, Pyrénées-Atlantiques), Archéologie des Pyrénées Occidentales, 5, p. 259-260.

\section{Bill $\mathbf{J}$.}

1973: Die Glockenbecherkultur und die frühe Bronzezeit im französischen Rhonebecken und ihre Beziehungen zur Südwestschweiz, Bâle.

1981 : Ein frühbronzezeitliches Tassenfragment aus Morges "Les Roseaux" Kanton Waadt, Archäologisches Korrespondenzblatt, 11, p. 195-196.

Bouchet J.-M., Burnez Cl.

1986: Le Bronze ancien de la Seugne. Sauvetage à SaintLéger-de-Pons, Archéologie Pontoise, 74, p. 1-8.

1989 : Un témoin chasséen en Saintonge, Bulletin de la Société Préhistorique Française, 86, 5, p. 132-133.

Bouchet J.-M., Burnez $\mathrm{Cl}$., Fouéré $\mathbf{P}$.

A paraître: La Grande Pigouille à Belluire (CharenteMaritime), Bulletin de la Société Préhistorique Française.

Briard J.

1984 : Les lumulus d'Armorique, Éd. Picard, Paris.

Burnez $\mathrm{Cl}$.

1976 : Le Néolithique et le Chalcolithique dans le Centre-Ouest de la France, Mémoires de la Société Préhistorique Française, 12, Ed. Klincksieck, Paris, 376 p., fig.

Cadot R., Joussaume R.

1988 : Puits de l'âge du Bronze à Avrillé (Vendée), Journées Archéologiques de Bretagne, p. 27-29.

Chaînet A.

1915 : Stations préhistoriques charentaises : Cordie, Merpins, Plassac, Pons, 8 p.

\section{Clouet M.}

1932: Note sur quelques objets en bronze des environs de Saintes, Association Française pour l'Avancement des Sciences, Bruxelles, p. 301-302.

Coffyn A., Gomez J., Bastien J.-M.

1973 : L’Âge du Bronze dans la collection Lugol à Mansle (Charente), Bulletin de la Société Préhistorique Française, 70, crsm 5, p. 138-144.

Daugas J.-P., Corde R., Laborde A., Liabeuf R., Pétrequin P. 1972: Nouveaux jalons campaniformes en Velay et en Bourbonnais, Bulletin de la Socièté Préhistorique Française, 69, crsm 3, p. 88-92.

Diot M.-F., Gomez J., Marinval Ph.

1987 : Le site fortifiè du Fort-des-Anglais à Mouthiers-surBoëme (Charente) et son environnement protohistorique, in : Préhistoire de Poilou-Charenles. Problèmes actuels, Actes du $111^{\mathrm{e}}$ Congrès national des Sociétés savantes, Commission de pré- et protohistoire, Poitiers 1986, Éd. du Comité des Travaux historiques et scientifiques, Paris, p. 331-346.
Frugier G., Andrieux P., Boudet R.

1983 : Les moules à bronze de l'habitat de la Lède du Gurp à Grayan-et-l'Hôpital (Gironde) (Bronze moyen), Journées de Paléométallurgie, Univ. de Technologie de Compiègne, 22-23 février 1983, p. 449-465 (reprographié).

Gachina J.

1975: Deux trouvailles anciennes de l'Àge du Bronze en Charente-Maritime, Bulletin de la Société Préhistorique Française, 72, crsm 3, p. 89-92.

Gaillard J.

1980: Les enclos funéraires prolohistoriques en Saintonge méridionale, Association Archéologique et Historique de Jonzac, 24 (reprographiè).

Gaillard J., Gomez J.

1975 : Quelques découvertes de l'âge du Bronze dans la région de Jonzac (Charente-Maritime), Bulletin de la Socièté Préhislorique Française, 72, crsm 5, p. 145-148.

Gomez J.

1980: Les cullures de l'Âge du Bronze dans le bassin de la Charente, Ed. P. Fanlac, Périgueux, 463 p., 84 fig.

1982 : Céramique à pastillage, cordons en arceau, décor cordé : vers une nouvelle approche du Bronze ancien dans le CentreOuest de la France, Bulletin de la Socièté Préhistorique Française, 79, ét. et tr. 10-12, p. 424-438.

1989 : L'Àge du Bronze dans le Centre-Ouest, Le Temps de la Préhistoire, Socièté Préhistorique Française, Éd. Archéologia, 1, p. 431-433.

Guilaine J., Blanchet J.-Cl., L'Helgouach J., Pétrequin P., Roussot-Larroque J.

1988: Le Chalcolithique en France, in: L'Elà del Rame in Europa, Congresso Internazionale di Viarreggio 15-18 oct. 1987, Rassegna di Archeologia, 7, Firenze, Ed. All'Insegna del Giglio, p. 211-253.

Joussaume R.

1981 : Le Néolithique de l'Aunis et du Poilou occidental dans son cadre atlantique, coll. Travaux du Laboratoire "AnthropologiePréhistoire-Protohistoire-Quaternaire Armoricains", ER n 27 du CNRS, Univ. de Rennes I, 624 p.

Joussaume R., Boiral $\mathbf{M}$.

A paraître: Céramiques du Bronze ancien à La Pointe du Grouin du Cou à La Tranche-sur-Mer (Vendée), Groupe Vendéen d'Études Préhisloriques, 23.

Kaenel G.

1976 : La fouille du Garage Martin, 1973. Précisions sur le site de Clendy à Yverdon (Néolithique et Âge du Bronze), Cahiers d'Archéologie Romande, 8.

Le Roux Ch.-T., Lecerf Y., Gautier M.

1981 : Les alignements du Moulin à Saint-Just avant, pendant et après l'érection des menhirs, in: Enclos funéraires et structures d'habilat en Europe du Nord-Ouest, Rennes, p. 121136. 
Letterlé $F$.

1987-1988 : Pays de la Loire, Noirmoutier-en-l'Ile, Luzéronde, Gallia Informations, 2, p. 179-180.

Longuet D., Peridy P., Rouzeau N.

1985 : Le site campaniforme de La Pointe de Grosse-Terre, commune de Saint-Hilaire-de-Riez (Vendée), Études Préhistoriques et Historiques des Pays de la Loire, 8, p. 31-42.

Musset G.

1885 : La Charente-Inférieure avant l'Histoire el dans la légende, La Rochelle.

Patte E.

1971: Quelques sépultures du Poitou, du Mésolithique au Bronze moyen, Gallia Préhistoire, 14, 1, p. 139-244.

Pautreau J.-P.

1976 : Le Camp Allaric commune d'Aslonnes (Vienne). Premiers résultats, L'Anthropologie, 80,3, p. 389-429.

1979 : Les rapports entre Artenaciens et Campaniformes et les débuts de la mètallurgie du cuivre dans le Centre-Ouest de la France, Bulletin de la Socièté Préhistorique Française, 76, crsm 4, p. 110-118.

Pautreau J.-P., Facon R., Gabet C., Hesse A., Robert P.-P. 1974: L'habital peu-richardien de La Sauzaie à Soubise (Charente-Maritime), fouilles de sauvetage, premiers résultats, Poitiers.

Pétrequin A.-M., Pétrequin P.

1978 : Le phénomène Campaniforme-Cordée. Chronologie et rapports avec les groupes régionaux, Bulletin de la Société Préhistorique Française, 75, ét. et tr. 10, p. 361-393.

Riquet R.

1959: L'Àge du Bronze autour de l'estuaire girondin, Bulletin de la Société d'Éludes Scientifiques d'Angers, nouvelle sér., 2, $89^{\circ}$ année, p. 62-72.
Roussot-Larroque $\mathbf{J}$.

1975 : Premier aperçu sur la céramique du Bronze ancien en Aquitaine, Bulletin de la Société Préhistorique Française, 72, crsm 7, p. 195.

1977 : Néolithisation et Néolithique ancien d'Aquitaine, Bulletin de la Socièté Préhistorique Française, 74, ét. et tr. 2, p. 559582.

1987: Les relations Aquitaine-Iles britanniques au Bronze ancien, in: Les relations entre le continent et les Iles britanniques à l'Âge du Bronze, Actes du Colloque de Lille dans le cadre du $22^{e}$ Congrès préhistorique de France, 2-7 sept. 1984, Sociétè Préhistorique Française, suppl. à la Revue Archéologique de Picardie, p. 17-56.

Roussot-Larroque J., Bouchet J.-M., Burnez Cl., Gruet M., Villes A.

1987: Sites de hauteur et de vallèe dans le Bassin de la Charente : l'exemple de la Seugne et du Né, in: Préhistoire de Poitou-Charentes, Problemes actuels, Actes du $111^{\mathrm{e}}$ Congrès national des Sociétés savantes, Commission de pré- et protohistoire, Poitiers 1986, Éd. du Comité des Travaux historiques et scientifiques, Paris, p. 347-384.

\section{Sireix M., Roussot-Larroque J.}

1968 : Le camp de Roquefort à Lugasson (Gironde), Bulletin de la Socièté Préhistorique Française, LXV, p. 524-544.

Taillet $\mathbf{M}$.

1953 : La station protohistorique de la Viaube, XIV Congrès préhislorique de France, Strasbourg-Melz, p. 607-625.

Verron G.

1977: Informations archéologiques de Haute et Basse-Normandie, Gallia Préhistoire, 22, 2, p. 357-406. 


\title{
RAPPORT SUR DU MATÉRIEL MALACOLOGIQUE DE LA PALUT À SAINT-LÉGER (CHARENTE-MARITIME)
}

\author{
par Yves GRUET
}

Liste du matériel trouvé à la résurgence sur la Seugne, au nord de Pons, et confié par le $D^{r}$ Michel Gruet à Yves Gruet.

Le matériel malacologique a été récolté juste au-dessus de la couche archéologique. Cette couche de coquilles très dense est elle-même surmontée d'une couche argileuse molle. Les difficiles conditions de fouille (pompages et échantillonnage à moitié dans l'eau) expliquent le mélange d'une petite quantité de Mollusques actuels reconnaissables à la fraîcheur des coquilles. La faune ancienne présente des tests blanchis (nom de genre précédé d'un astérisque).

\section{MOLLUSQUES DULCICOLES}

\section{Gastéropodes PROSOBRANCHES}

Famille des Nerilidae

Theodoxia fluviatilis (Linné, 1758) : 4 exemplaires (colorés, actuels). Espèce d'eaux courantes ou stagnantes, eau douce et saumâtre jusqu'à $16 \%$ (Paléarctique occidental; en Mer du Nord et Baltique, en eau saumâtre).

Famille des Valvatidae

* Valvala (très probablement V.piscinalis) (Müller, 1774) : nombreux exemplaires de toutes tailles. Espèce d'eaux pures, stagnantes ou à faible courant, dans le fond vaseux (Paléarctique).

Famille des Hydrobiidae

* Bithynia tentaculata (Linné, 1758) : très nom- breux exemplaires de toutes tailles. Espèce de rivières, canaux, étangs; eaux saumâtres jusqu'à $12 \%$ (Paléarctique).

Famille des Bithynellidae

* Bithynella gibba (Draparnaud, 1801) : quelques exemplaires. Espèce des sources, eaux claires (Germain, 1930, p. 631).

\section{Gastéropodes pulmones Basommatophores}

Famille des Physidae

* Physa acula (Draparnaud, 1805) : nombreux exemplaires. Espèce de rivières, ruisseaux et canaux : sur les pierres et les plantes (Europe occidentale et pays méditerranéens).

Famille des Lymnaeidae

* Lymnae palustris (Müller, 1774) : nombreux exemplaires. Espèce d'eaux douces stagnantes, marais (Holarctique).

* Lymnae auricularia (Linné, 1758) : nombreux exemplaires. Espèce d'eaux douces stagnantes ou à faible courant, végétation riche (Paléarctique).

* Lymnae stagnalis (Linné, 1758) : nombreux exemplaires de toutes tailles. Espèce d'eaux douces stagnantes et rivières à faible courant (Holarctique).

\section{Famille des Planorbidae}

* Planorbis corneus (Linné, 1758) : très nombreux exemplaires de toutes tailles (jeunes et adultes). Espèce d'eaux stagnantes à végétation riche (Europe, Asie occidentale).

* Anisus planorbis (Linné, 1758)= Planorbis 
planorbis Linné = Planorbis umbilicatus Müller : très nombreux exemplaires de toutes tailles. Espèce d'eaux stagnantes ou à faible courant, à végétation riche (Europe et Asie occidentale, Afrique du Nord); espèce proche d'Anisus carinatus (Müller, 1774).

* Anisus vortex (Linné, 1758) : nombreux individus. Espèce d'eaux douces stagnantes ou à faible courant, à végétation riche (Europe et Asie occidentale).

* Anisus contortus (Linné, 1758) : rares exemplaires. Espèce d'eaux douces stagnantes ou à faible courant, à végétation riche, peut ètre trouvée en eau légèrement saumâtre $5 \%$ (Paléarctique : toute l'Europe et l'Asie septentrionale).

* Anisus crista (Linné, 1758) : petite espèce (3 $\mathrm{mm})$ assez abondante. Espèce d'eaux douces et faiblement saumâtres, sur le fond, sur des plantes aquatiques ou sur des corps flottants (Holarctique).

* Anisus complanatus (Linné, 1758): assez abondante. Espèce d'eaux douces stagnantes à végétation riche (Europe et Asie occidentale).

Famille des Ancylidae

* Acroloxus lacustris (Linné, 1758) : quelques exemplaires. Espèce d'eaux stagnantes ou à faible courant, sur les plantes aquatiques (presque toute l'Europe).

\section{Gastéropodes pulmones STylommatophores}

Famille des Succineidae

* Succinea elegans (Risso, 1826) = Oxyloma elegans Risso : 3 exemplaires. Espèce se trouvant à proximité immédiate de l'eau, sur la vase ou sur les plantes : vit hors de l'eau sur les plantes hélaphyres ayant leurs racines sous l'eau (roseaux) (Europe, Afrique du Nord, Asie occidentale et septentrionale).

\section{MOLLUSQUES BIVALVES D'EAU DOUCE}

Famille des Sphaeriidae

* genres Sphaerium et Pisidium : assez nombreux exemplaires dont les petits ont encore leurs valves jointes. La détermination spécifique pourra ètre donnée ultérieurement. Espèce vivant souvent, notamment les jeunes, entre les racines des plantes bordant les plans d'eau ou les ruisseaux.

\section{MOLLUSQUES TERRESTRES}

Famille des Cochlicopidae

Actuel? Cochlicopa (cf. lubrica, Müller, 1774) : quelques exemplaires. Espèce des endroits humides, sous la mousse, les feuilles mortes. Parfois des stations plus sèches (Holarctique : Europe, Afrique du Nord).

Actuel? Pyramidula rupestris (Draparnaud, 1801) : nombreux exemplaires dont certains sont encore un peu colorés (Hélicidés sp.) : deux exemplaires.

\section{DIVERS}

- Mollusques frais, encore bruns (actuels) : 1 Bithynia tentaculata, 2 Physa acuta, 1 Anisus vortex. - Un morceau de fossile : Bryozoaire (marin). - Oogone de Characées.

\section{**}

Si l'on considère que tous les Mollusques d'eau douce ont vécu ensemble, le biotope pouvait être une eau douce riche en végétation aquatique, une eau assez pure pour permettre une grande diversité de la faune malacologique. Il faut exclure l'eau saumâtre ou de l'eau "pourrissant" vite au printemps. Il faut exclure un ruisseau d'eau courante rapide. Par contre les Bithynellidae indiquent une eau de source. Il faut enfin remarquer que la faune aquatique actuelle est d'une grande pauvreté et d'une très faible diversité.

Yves Gruet ${ }^{3}$

3. Laboratoire de Biologie Marine, Université de Nantes, Faculté des Sciences, 58, boulevard Michelet, 44000 Nantes. 